\title{
WP/20/252
}

IMF Working Paper

Monetary Policy Surprises and Inflation Expectation Dispersion

by Francesco Grigoli, Bertrand Gruss and Sandra Lizarazo 


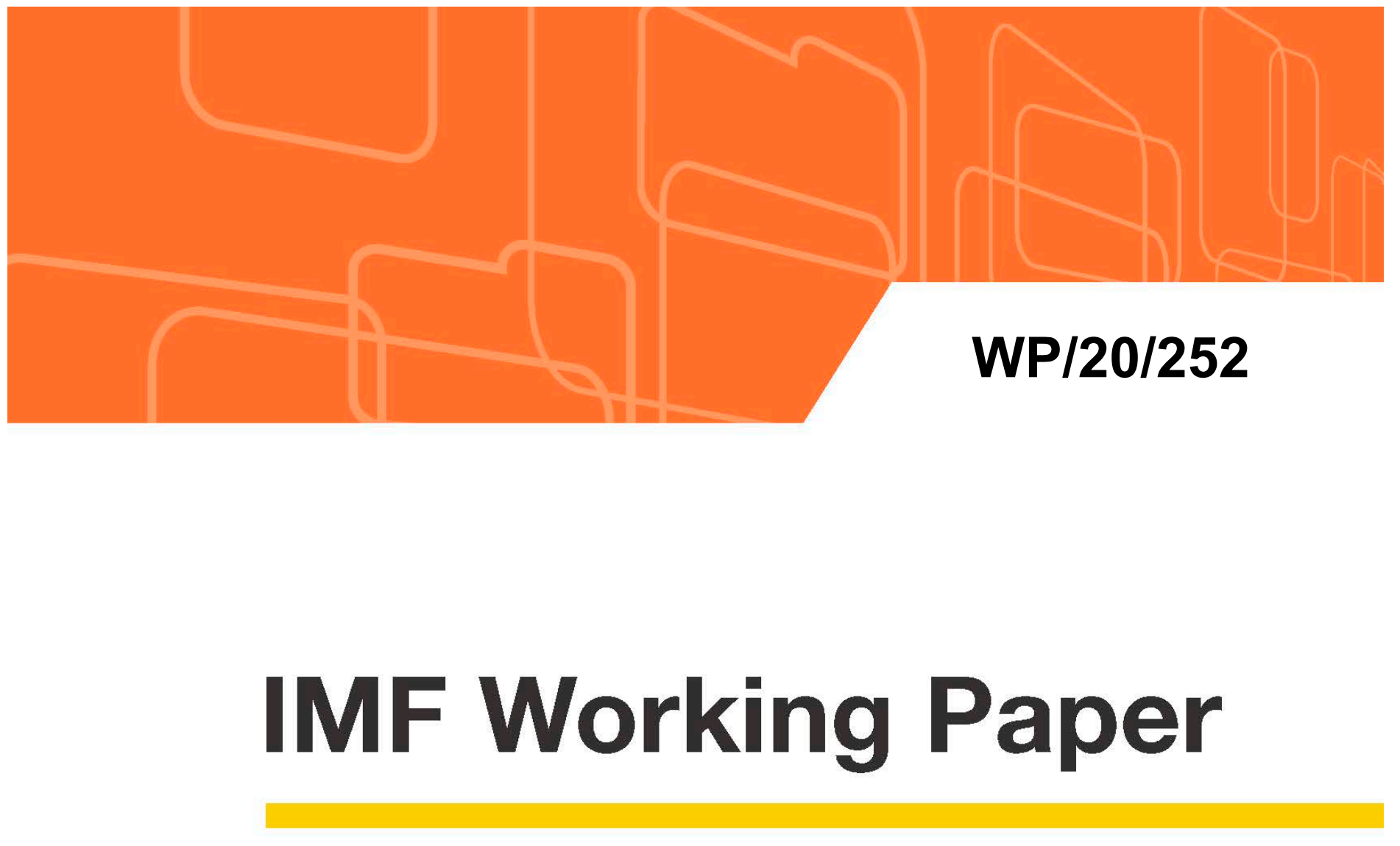

\section{Monetary Policy Surprises and Inflation Expectation Dispersion}

by Francesco Grigoli, Bertrand Gruss and Sandra Lizarazo 


\title{
Monetary Policy Surprises and Inflation Expectation Dispersion*
}

\author{
Francesco Grigoli \\ IMF
}

\author{
Bertrand Gruss \\ IMF
}

\author{
Sandra Lizarazo \\ IMF
}

\begin{abstract}
Anchoring of inflation expectations is of paramount importance for central banks' ability to deliver stable inflation and minimize price dispersion. Relying on daily interest rates and inflation forecasts from major financial institutions in the United States, we calculate monetary policy surprises of individual analysts as the unexpected changes in the federal funds rate before the meetings of the Federal Reserve Board. We then assess the effect of monetary policy surprises on the dispersion of inflation expectations, a proxy for the extent of anchoring, which is based on the same analysts' inflation projections submitted after the Fed meetings. With an identification strategy that hinges on a tight window around the Fed meetings, we find that monetary policy surprises lead to an increase in the dispersion of inflation expectations up to nine months after the policy meeting. We rationalize these results with a partial equilibrium model that features rational expectations and sticky information. When we allow the degree of information rigidity to depend on the realization of firm-specific shocks, the theoretical results are qualitatively consistent and quantitatively close to the empirical evidence.
\end{abstract}

Keywords: Anchoring, disagreement, dispersion, information rigidity, inflation expectations, sticky information.

JEL Codes: D84, E31, E52

*Francesco Grigoli, fgrigoli@imf.org; Bertrand Gruss, bgruss@imf.org; Sandra Lizarazo, slizarazo@imf.org. The views expressed in this Working Papers are those of the authors and do not necessarily represent those of the IMF or IMF policy. Working Papers describe research in progress by the authors and are published to elicit comments and to encourage debate. We thank, without implicating, Vassili Bazinas, Nina Biljanovska, Francesca Caselli, Nigel Chalk, Gabriel Di Bella, Jose M. Mota, Malhar Nabar, Valeriu Nalban, Roberto Piazza, the US Department of Treasury, and the participants to the 13th International Conference on Computational and Financial Econometrics for their comments and suggestions. 


\section{Contents}

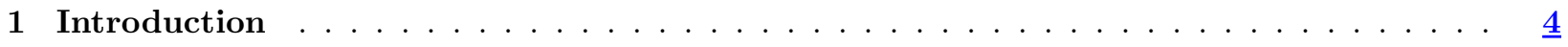

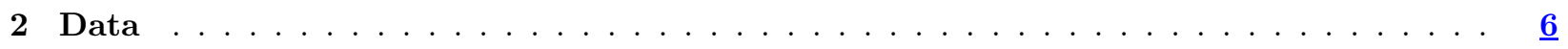

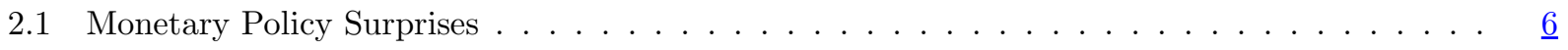

2.2 Dispersion of Inflation Expectations $\ldots \ldots \ldots \ldots \ldots \ldots$

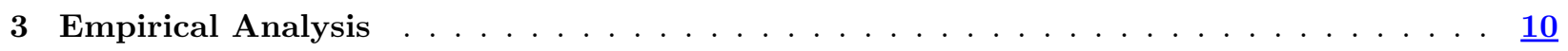

3.1 The Response of Inflation Expectation Dispersion to Monetary Policy Surprises . . . . . . . 11

3.2 Narrower Time Windows . . . . . . . . . . . . . . . . . . . 12

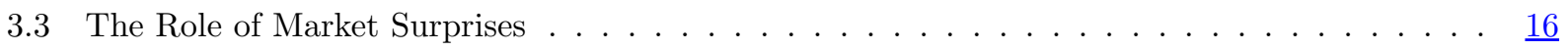

3.4 Deviations From the Inflation Target $\ldots \ldots \ldots \ldots \ldots \ldots \ldots \ldots \ldots$

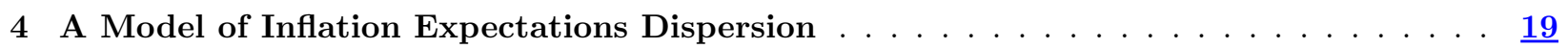

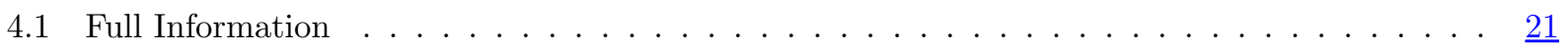

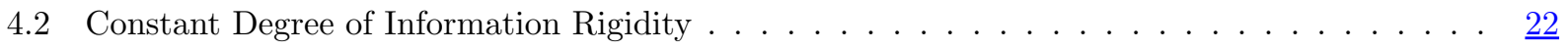

4.3 Aggregate State-Dependent Degree of Information Rigidity $\ldots \ldots \ldots \ldots \ldots$

4.4 Firm State-dependent Degree of Information Rigidity . . . . . . . . . . . . . $\underline{29}$

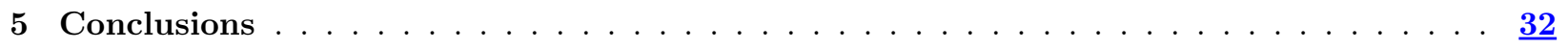

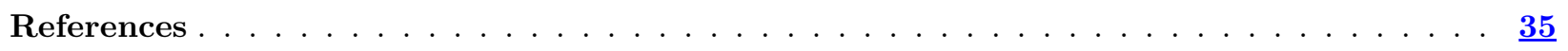

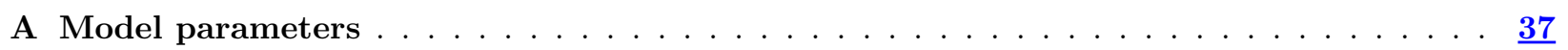




\title{
List of Figures
}

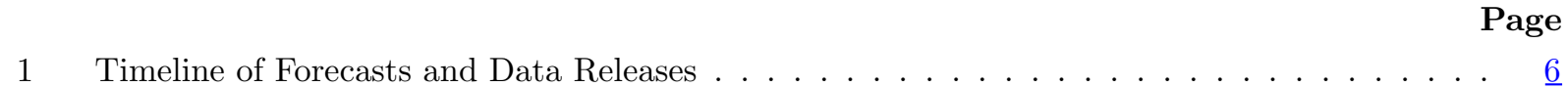

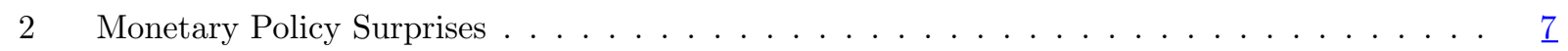 \\ 3 Cumulative Distribution of Inflation Expectation Dispersion at Different Horizons _. . . . $\underline{8}$ \\ 4 Inflation Expectations Dispersion at Different Horizons . . . . . . . . . . . . . . . $\underline{9}$ \\ 5 Effects of Monetary Policy Surprises on the Term Structure of Inflation Expectation Dispersion $\underline{14}$

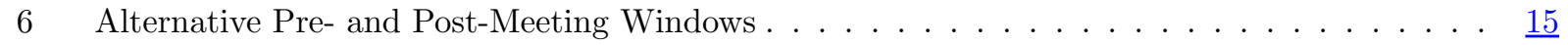 \\ 7 Response of Inflation Expectation Dispersion to an Interest Rate Shock, Constant Stickiness . $\underline{25}$ \\ 8 Average Response of Inflation Expectation Dispersion to an Interest Rate Shock, Constant

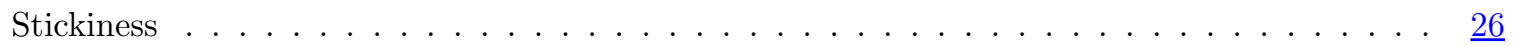 \\ 9 Response of Inflation Expectation Dispersion to a Persistent Interest Rate Shocks, Varying

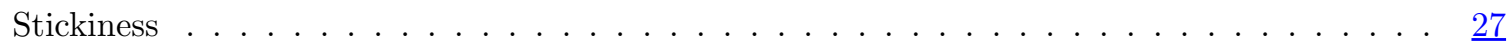 \\ 10 Response of Inflation Expectation Dispersion to a Persistent Interest Rate Shock, Aggregate

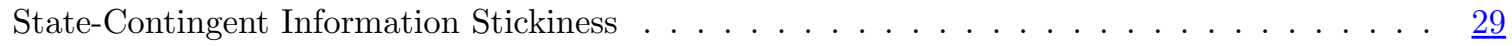 \\ 11 Average Response of Inflation Expectation Dispersion to an Interest Rate Shock, Aggregate

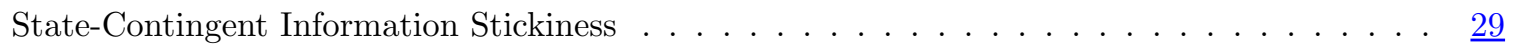 \\ 12 Response of Inflation Expectation Dispersion to a Persistent Interest Rate Shock, Firm State-

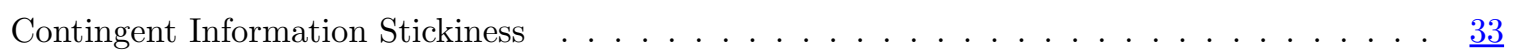 \\ 13 Average Response of Inflation Expectation Dispersion to an Interest Rate Shock, Firm State-

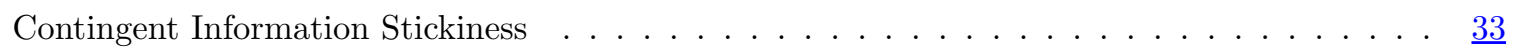

\section{List of Tables}

Page

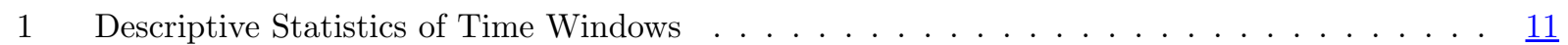

2 Effects of Federal Funds Rate Surprises on Inflation Expectation Dispersion . . . . . . . . $\underline{13}$

3 Effects of High-Frequency Monetary Policy Shocks on Inflation Expectation Dispersion . . . . $\underline{16}$

4 Effects of Individual and Market Surprises on Inflation Expectation Dispersion . . . . . . 17

5 Effects of Individual and NS-Based Market Surprises on Inflation Expectation Dispersion . . $\underline{18}$

6 Effects of Federal Funds Rate Surprises on Inflation Expectation Anchoring . . . . . . . . . 19

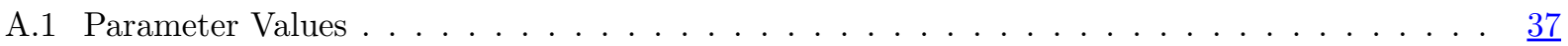




\section{Introduction}

Anchoring of inflation expectations is considered to have played a key role in reducing the persistence of inflation and its sensitivity to fluctuations in activity and other factors (Bernanke, 2007; Mishkin, 2007). For instance, real shocks have a less persistent effect on inflation dynamics and the exchange rate pass-through is lower when expectations are better-anchored (Fuhrer, 2010; Bems et al., 2018; Carrière-Swallow et al., 2020). In addition, anchoring affects the transmission of monetary policy, with an expansionary stance potentially boosting activity and lowering inflation when expectations are poorly coordinated (Hoffmann and Hürtgen, 2016). Disagreement among inflation forecasters may also lead to an inefficient dispersion in actual prices, even if inflation is stable at low levels. ${ }^{1}$ While several studies explored the drivers of inflation forecast disagreement (Mankiw et al., 2003; Dovern et al., 2012), there is still limited understanding on how monetary policy actions affect inflation expectation dispersion. This paper aims at filling this void.

We first estimate empirically the causal effect of monetary policy surprises in the United States on the dispersion of inflation expectations among individual forecasters. Relying on daily data at the analyst level from major financial institutions, we compute monetary policy surprises of individual analysts as the unexpected changes of the federal funds rate with respect to the forecasts produced in a short window of time prior to the Fed meetings. ${ }^{2}$ We document that surprises concentrated in the run-up to the global financial crisis, the crisis itself, and post-2015 - which is when agents expected an acceleration in the normalization of monetary policy that turned out to be slower. We then assess the impact of these monetary policy surprises on the dispersion of inflation expectations for different horizons, which is based on the same analysts' inflation projections produced right after the Fed meetings (i.e., the moment in which they get surprised).

With an identification strategy that hinges on a tight window around the Fed meetings, we find evidence of a temporary de-anchoring of inflation expectations. That is, surprises in federal funds rate decisions lead to a significant increase in the dispersion of inflation expectations for horizons up to nine months after the policy rate decision is taken. The effect of monetary surprises on dispersion of inflation expectations at longer horizons is not statically significant.

Then, to rationalize the empirical results, we propose a partial equilibrium rational expectations model with sticky information, in the spirit of Mankiw and Reis (2002). We contend that information rigidity is essential to explain the empirical patterns. To make our point, we show that the predictions of a model with full information are not consistent quantitatively nor qualitatively with the observed dispersion of inflation expectations in response to monetary policy surprises. Instead, introducing sticky information is key to generate results that are qualitatively in line with our empirical findings. We finally extend the model to allow the degree of information rigidity to depend on the realization of firm-specific shocks (rather than aggregate ones), and conclude that the theoretical results are qualitatively consistent and quantitatively close to the empirical ones.

From a policy perspective, our results show that there is room to further refine the communication strategy of monetary policy. Specifically, improvements in the Fed's communication aimed at managing

\footnotetext{
${ }^{1}$ The literature identifies the low dispersion of individual inflation forecasts as a key feature of inflation expectations in economies that feature a strong nominal anchor (Kumar et al., 2015).

${ }^{2}$ Monetary policy in the United States does not exclusively rely on the federal funds rate. Other tools include open market operations targeting longer maturities (often used at the zero lower bound), reserve requirements, and interest on reserves. Moreover, Gürkaynak et al. (2005), Gertler and Karadi (2015), and Nakamura and Steinsson (2018) point out that forward guidance has became an increasingly important tool in the last 15 years to influence rates at longer maturities. In what follows, we limit the analysis to the federal funds rate, which is the variable for which we have individual analysts' forecasts.
} 
inflation expectations would reduce information rigidity and minimize surprises, which in turn would lead to less dispersion across analysts. Or, put differently, the Fed could play a stronger coordinating role via its monetary policy decisions when they are accompanied by clear and effective communication. This would allow to maintain inflation expectations better anchored even at shorter horizons, which is when the credit channel is less effective.

Literature Our paper primarily relates to the literature examining the disagreement across forecasters about future inflation and its drivers. In an early contribution, Mankiw et al. (2003) analyze several surveys for the United States and document a substantial dispersion in inflation expectations. They find that disagreement is larger among consumers than among experts, even though the time-series patterns are similar; and that it increases when inflation is high, when inflation moves a lot, and during recessions. They also find that the sticky information model of Mankiw and Reis (2002) is capable of replicating several features about the dispersion of inflation expectations. Patton and Timmermann (2010) focus on the termstructure of disagreement among forecasters in the United States and argue that heterogeneity in priors or models, rather than on information signals, are more important for explaining the dispersion in expectations. Using the ECB Survey of Professional Forecasters, Andrade and Le Bihan (2013) show that forecasters fail to systematically update their forecasts and disagree when updating. They argue that Mankiw and Reis (2002) and Sims (2003) models of sticky and noisy information are qualitatively consistent with the empirical findings but cannot quantitatively replicate the error and disagreement observed in the data. We contribute to this strand of literature by documenting a novel fact about inflation expectation disagreement, that it increases in response to policy rate shocks, and by showing that this fact can be rationalized within a sticky information framework.

Our paper is also close to the literature that identifies monetary policy shocks with high-frequency data (Gertler and Karadi, 2015; Nakamura and Steinsson, 2018; Jarociński and Karadi, 2020) and their effects on public expectations (Del Negro and Eusepi, 2011; Coibion and Gorodnichenko, 2012; Melosi, 2017). Differently from these studies, we identify (policy rate) shocks at the analyst level-rather than for the market-relying on high frequency data.

Finally, our analysis is related to the literature that explores the relationship between monetary policy and forecast disagreement. Dovern et al. (2012) document that inflation forecast disagreement is related to the degree of independence of the monetary authority. Gürkaynak et al. (2010), Capistrán and RamosFrancia (2010), and Beechey et al. (2011) explore whether adopting an inflation targeting regime has an effect on the level or the dispersion of inflation expectations. Brito et al. (2018) complement this analysis by exploring the role of the transparency of the monetary framework (beyond the adoption of inflation targeting) on forecast disagreement. We contribute to this literature by exploring the effect that monetary policy actions, rather than features of the monetary framework, have on forecast disagreement among agents.

The rest of the paper is organized as follows. Section 2 presents the data and documents the construction of the measures of monetary policy surprises and inflation expectation dispersion. Section 3 introduces the identification strategy based on the tight window around the Fed meetings and presents the empirical results. Section 4 proposes a theoretical model based on sticky information and goes over alternative characterizations of the inflation expectation formation mechanisms. Section 5 concludes. 


\section{Data}

Our data consists of daily inflation and federal funds rate forecasts for the United States at the analyst level between November 18, 2002 and December 18, 2018 obtained from Bloomberg. The dataset includes forecasts of 496 analysts from major financial institutions worldwide on inflation and the federal funds rate, submitted at irregular intervals (so the panel is unbalanced). ${ }^{3}$

The timeline of the inflation and federal funds rate forecasts is a key feature of our dataset, which we use to identify the impact of monetary policy surprises on inflation dispersion. Figure 1 illustrates this timeline. Each analyst can submit a forecast for the federal funds rate, $p_{t-1+\gamma \mid t-1}^{e}$, for period $t-1+\gamma$ at any time during $[t-1, t-1+\gamma)$. Then, the analyst observes the federal funds rate decision $p_{t-1+\gamma \mid t-1+\gamma}^{r}$, which takes place and is announced in correspondence of the policy meeting at $t-1+\gamma$. Subsequently, the same analyst prepares the inflation forecast $\pi_{t+h \mid t}^{e}$ during $(t-1+\gamma, t]$ - that is, after the federal funds rate announcement - for horizon $t+h$ with $h=\{-\epsilon, 3,6,9,12\} .{ }^{4}$ Finally, actual inflation for period $t+h$, $\pi_{t+h \mid t+h+\theta}^{r}$, is released at $t+h+\theta$.

It should be noted that for inflation, in the case of horizon $t-\epsilon$, the analyst actually submits a backcast for the month that just went by. For all other horizons, $h=\{3,6,9,12\}$, the analyst submits a forecast for a future period. In all cases, the inflation release takes place within 15 days after the end of the month for which the forecast is made. Importantly, analysts have the chance to revise and re-submit their estimates at any time.

Figure 1: Timeline of Forecasts and Data Releases

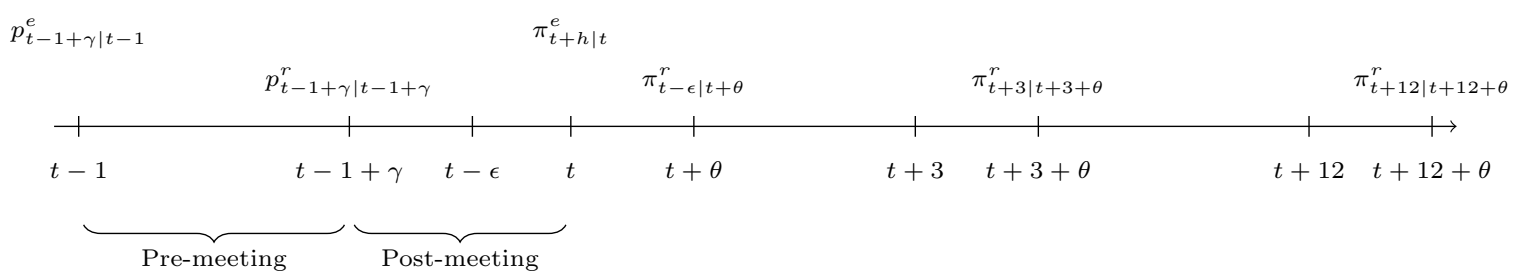

\subsection{Monetary Policy Surprises}

The first step to assess the impact of surprises about central bank decisions on the dispersion of inflation expectations is to construct a variable capturing surprises at the individual's level. These surprises are computed as the absolute value of the deviation of the individuals' expected federal funds rate from the actual rate announced at the time of the central bank meeting: ${ }^{5}$

$$
s_{i, t-1+\gamma \mid t-1}^{i^{e}}=\left|p_{i, t-1+\gamma \mid t-1}^{e}-p_{t-1+\gamma \mid t-1+\gamma}^{r}\right|
$$

\footnotetext{
${ }^{3}$ In the United States, the Federal Open Market Committee must meet at least four times each year in Washington, D.C. Since 1981, eight regularly scheduled meetings have been held each year at intervals of five to eight weeks. Submission for which the name of the analyst is not reported are dropped from the sample.

${ }^{4}$ While it would be interesting to consider longer horizons, analysts are asked to submit inflation forecasts up to one year ahead.

${ }^{5}$ The surprise is computed in absolute value as the question of interest is whether monetary surprises - regardless of whether they are positive or negative- lead to an increase in the extent of dispersion of analysts' forecasts.
} 
where we set the pre-meeting window (i.e., time span between the moment in which the analyst submits her latest forecast, $t-1$, and the federal funds rate announcement day, $t-1+\gamma$ ) to a maximum of 45 days. This time window broadly corresponds to the number of days between federal funds rate announcements.

The assumption underlying the construction of the variable is that all information that is available to the analyst at the beginning of the 45-day window is already incorporated in the analyst's forecast and does not show up as spurious variation in the shock variable. Of course, new information (e.g., new events or data releases) can come in during these 45 days, making the analyst's forecast outdated and our shock identification invalid. However, this would happen only if the analyst does not re-submit her forecast - which she can do at any time - or to the extent that this new information is systematically correlated with the forecast or the federal funds rate decision, thereby resulting in a correlation with the surprise variable. While the time windows is set to 45 days, on average analysts submit their (latest) forecast for the federal funds rate only 9 days before the meeting.

Figure 2 shows the monthly average of our surprise variable. Average surprises were quite frequent, albeit small, between 2002 and 2007 but they became larger in the period leading up to the global financial crisis. Since then, the need for accommodative monetary conditions and the proximity to the zero lower bound made the Fed's decisions on the federal funds rate more predictable. Since 2015 average surprises increased again as agents began to expect an acceleration in the normalization of monetary policy in the United States, which only started later and slower than expected.

Figure 2: Monetary Policy Surprises

(Percentage points)

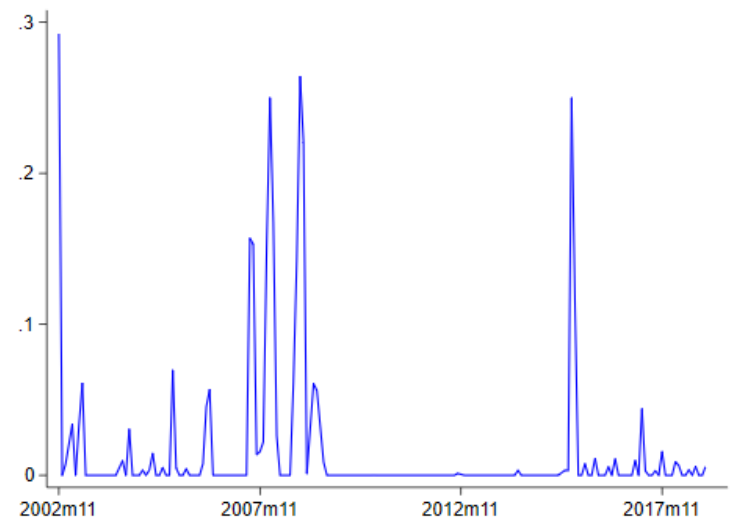

Source: Bloomberg and authors' calculations.

Notes: The line denotes the monthly average of the federal funds rate surprises across analysts.

\subsection{Dispersion of Inflation Expectations}

The next step is to construct a measure of inflation expectation dispersion. We do it by taking the absolute value of the deviation of the individual's inflation forecast from the average forecast across all other analysts:

$$
d_{i, t+h \mid t}^{\pi^{e}}=\left|\pi_{i, t+h \mid t}^{e}-\frac{1}{N-1}\left(\sum_{i=1}^{N} \pi_{i, t+h \mid t}^{e}-\pi_{i, t+h \mid t}^{e}\right)\right|
$$


where we set the post-meeting window (i.e., the time span between the federal funds rate announcement, $t-1+\gamma$, and the moment in which analyst $i$ submits the inflation forecast, $t$ ) to a maximum of 30 days. Similar to surprises, we take the absolute value since positive and negative deviations occurring at the same time cancel out.

Panel (a) of Figure 3 presents the cumulative distribution of inflation expectation dispersion for the United States at different horizons. Unsurprisingly, the shorter the horizon the higher is the frequency around zero, indicating that uncertainty about the inflation outcome is larger when the release is further into the future. As an example, the standard deviation of inflation expectation dispersion for the month that just finished (i.e., $h=-\epsilon$ ) is 27 basis points. For the farthest horizon (i.e., $h=12$ months), the standard deviation almost doubles at 50 basis points. ${ }^{6}$

Figure 3: Cumulative Distribution of Inflation Expectation Dispersion at Different Horizons (Percentage points)

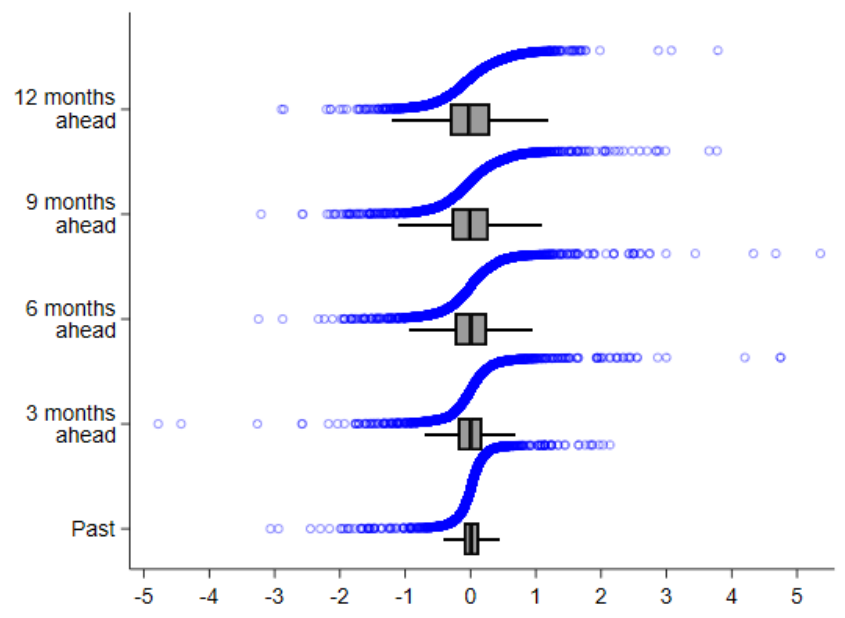

Source: Bloomberg and authors' calculations.

Notes: The dots denote the observations, the vertical lines of the box plots denote the medians, and the horizontal lines of the box plots denote the interquartile ranges.

Figure 4 displays the inflation expectation dispersion over time for all horizons. In particular, we plot the cross-country median aggregated at the monthly frequency, which hovers between 0 and 0.5 percentage points for most of the sample across all horizons, albeit it tends to be larger for the farther horizons. For instance, the average of the median inflation expectation dispersion over time is 0.17 percentage points for $h=-\epsilon$ and it grows to 0.35 percentage points for $h=12$. However, the dispersion spikes around the global financial crisis (2008-09) and at the time of the taper tantrum announcement (May 2013); large movements are also present at the beginning of the sample but are less common across horizons. The interquartile range around the median is wider for larger horizons, confirming the evidence of Figure 3, and is wider around peaks of median inflation expectation dispersion.

At first sight, large variability in the dispersion of inflation expectations and in monetary policy surprises

\footnotetext{
${ }^{6}$ The sample of analysts is not the same across horizons. As a result, the number of observations varies between 3,981 at $h=-\epsilon$ and 5,594 at $h=12$. Reducing the sample to only those analysts that submitted inflation forecasts for all horizons does not affect the descriptive statistics.
} 
tend to coincide. Taking advantage of the timing of the inflation forecast submission, we now turn to assessing the causal effect of monetary surprises on inflation dispersion.

Figure 4: Inflation Expectations Dispersion at Different Horizons

(Percentage points)
(a) Past
(b) 3 months ahead

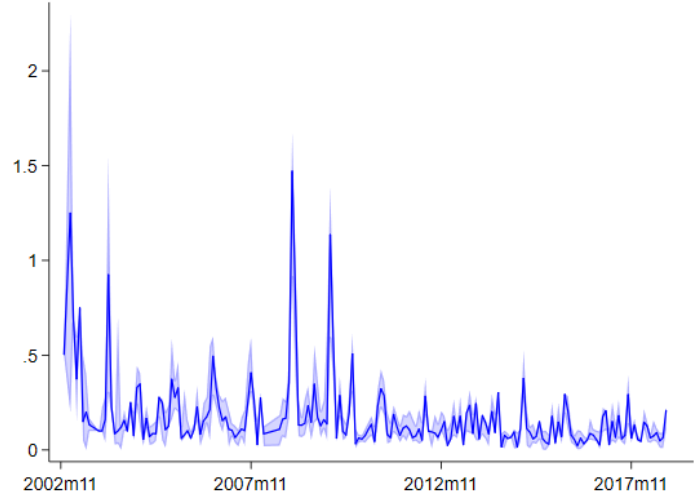

(c) 6 months ahead

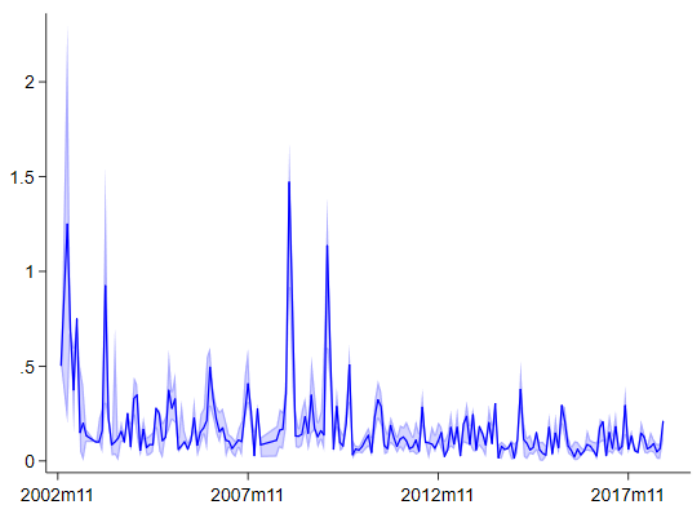

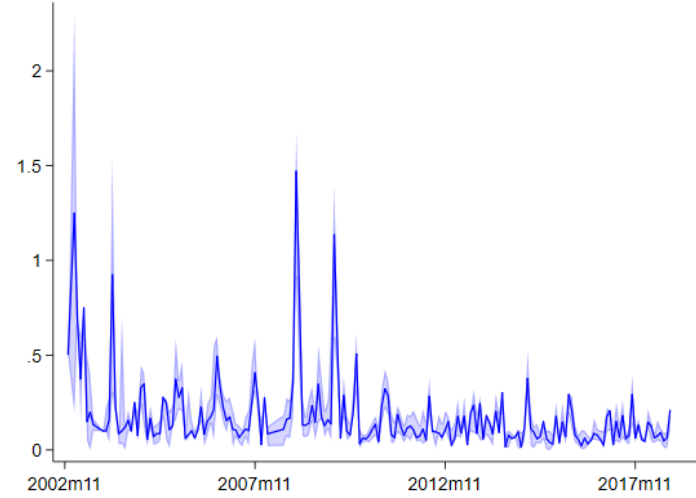

(d) 9 months ahead

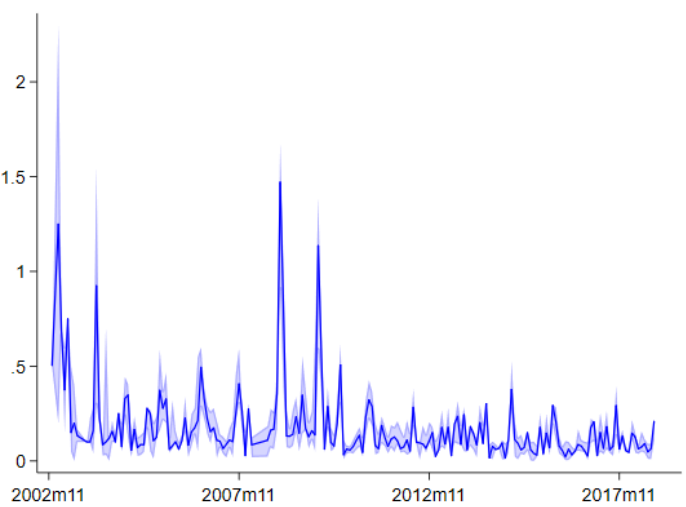

(e) 12 months ahead

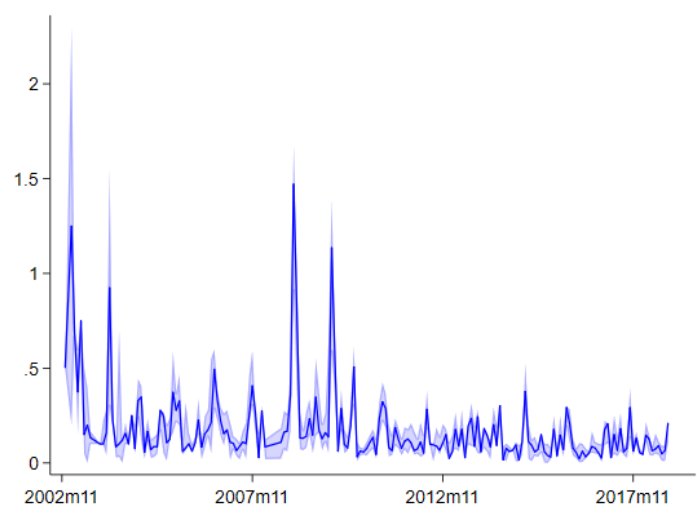

Source: Bloomberg and authors' calculations.

Notes: The lines denote the monthly average of the median inflation dispersion across analysts, and the shaded areas denote interquartile ranges. 


\section{Empirical Analysis}

To assess the impact of analysts' surprises about policy rate decisions, $s_{i, t-1+\gamma \mid t-1}^{i^{e}}$, on inflation expectation dispersion, $d_{i, t+h \mid t}^{\pi^{e}}$, we estimate the following panel regression:

$$
d_{i, t+h \mid t}^{\pi^{e}}=\beta s_{i, t-1+\gamma \mid t-1}^{i^{e}}+\phi_{i}+\mu_{i, t+h}
$$

where $\phi_{i}$ denotes the analyst fixed effects, which capture any systematic bias in each analyst's forecasts; and $\mu_{i, t+h}$ is an i.i.d. error term. The surprise variable is lagged by one period so that, even in the case in which inflation expectation dispersion is calculated at $h=-\epsilon$, the surprise always precedes the inflation forecast.

The identification strategy is based on the tight window around the Fed meetings. First, we make sure that the post-meeting window - the time between the moment in which analysts get surprised by the interest rate decision, $t-1+\gamma$, and the moment in which they submit their inflation forecasts, $t$ - is narrow. A sufficiently short time interval between these two events reduces the probability that other confounding factors (potentially correlated with the surprises or the inflation expectation dispersion) bias the estimates of the impact of monetary surprises on the dispersion of inflation expectations. Unfortunately, in some cases analysts do not update their inflation projections for a long period after a policy decision has been announced. Thus, as discussed in Section 2, we take advantage of the richness of our dataset and purge from the sample those observations for which the pre-meeting window is longer than 30 days - a relatively short time span that reduces the likelihood of other events conditioning the analysts' forecasts. In the resulting sample, analysts submit their inflation forecasts, on average, 16 days after the federal funds rate announcement. Moreover, in a series of robustness tests, we reduce shorten the post-meeting window in subsequent steps to 25, 20, 15, and 10 days, which improves the identification but inevitably reduce the number of observations.

Second, we allow for a narrow pre-meeting window - the time between the analyst's submission of her policy rate forecast and the Fed announcement. The concern is that analysts could become aware of new information after they submit the forecast for the federal funds rate. If analysts do not re-submit their interest rate forecasts and the new information is correlated with the surprise variable, the estimates of the effect of monetary policy surprises on inflation expectations' dispersion would be biased (Nakamura and Steinsson, 2018). To alleviate this concern, we construct alternative surprise variables, setting a lower ceiling on the number of days between the submission of the analyst's interest rate forecast and the federal funds rate announcement day to 30,20,10, and 5 days. Using narrower pre-meeting windows reduces the chances for other factors to bias our estimates - but, again, at a cost of reducing number of observations. ${ }^{7}$

To test the robustness of our results, we estimate the specification in equation (3) with all possible combinations of pre- and and post-meeting windows' length. As shown in Table 1, when the narrowest pre- and post-meeting windows are used -5 and 10 days, respectively) - the average time spans between submitting the federal funds rate forecast and the announcement day, and between the announcement day and submitting the inflation forecast, are only 2.5 and 5.9 days, respectively.

A few other aspects of the specification in equation (3) deserve some discussion. We refrain from including time fixed effects in the specification. In fact, all common events that affect all the forecasters at the same

\footnotetext{
${ }^{7}$ Narrowing the pre-meeting window also allows to isolate those analysts that are relatively more "active" in submitting forecasts. In other words, a tighter window before the announcement day excludes those analysts that likely incur fixed costs to acquire and process new information and, as a result, refrain from revising and re-submitting their forecast. Yet, there still exists the possibility that analysts incur such fixed costs and, due to those, opt to submit their forecasts only a few days before the federal funds rate announcement.
} 
Table 1: Descriptive Statistics of Time Windows

(Percentage points)

\begin{tabular}{lccccc}
\hline Variable & Obs & Mean & SD & Min & Max \\
\hline Pre-meeting window, holding post-meeting & window $<30$ days & & & \\
45-day window & 2,210 & 9.1 & 8.2 & 0 & 43 \\
30-day window & 2,105 & 7.6 & 5.4 & 0 & 29 \\
20-day window & 1,893 & 6.3 & 3.3 & 0 & 19 \\
10-day window & 1,642 & 5.2 & 1.8 & 0 & 9 \\
5-day window & 318 & 2.5 & 1.3 & 0 & 4 \\
Post-meeting window, holding pre-meeting window $<45$ days & & & \\
30-day window & 2,210 & 15.6 & 7.4 & 0 & 29 \\
25-day window & 2,035 & 14.6 & 6.8 & 0 & 24 \\
20-day window & 1,446 & 11.4 & 5.4 & 0 & 19 \\
15-day window & 782 & 7.2 & 3.8 & 0 & 14 \\
10-day window & 657 & 5.9 & 3.1 & 0 & 9 \\
\hline
\end{tabular}

Source: Bloomberg and authors' calculations.

time should be already contemplated when the federal funds rate forecast is submitted. To the extent that this happens, the shock variable is likely to be highly correlated across analysts and including time fixed effects would absorb that variation biasing the coefficient on the shock variable.

Also, it should be noted that the estimation of the effect on inflation expectation dispersion at horizon $h=-\epsilon$ reveals something different compared to the estimations using inflation expectation dispersion at horizons $h=\{3,6,9,12\}$. When assessing the impact of the surprise on inflation expectation dispersion at a future horizon, an analyst necessarily needs to form a view about future policy actions. In contrast, there is no uncertainty about policy actions for the past, as these have already been observed. ${ }^{8}$ Thus, the coefficient on the shock would capture whether the analysts' disagreement changes with respect to the yetunpublished inflation over the preceding month. We argue that using horizon $h=-\epsilon$ allows isolating the effect of "revealed information" through the Fed actions as - in response to a surprise about the federal funds rate - analysts may think that the central bank had some information that they could not take into account or had not given the right weight. ${ }^{9}$

\subsection{The Response of Inflation Expectation Dispersion to Monetary Policy Sur- prises}

Table 2 reports the baseline results of the impact of a 100-basis point surprise in the federal funds rate on inflation expectation dispersion. Each column corresponds to a different horizon, starting with the month that already finished $(h=-\epsilon)$ in column (1), up to the dispersion for the one-year ahead forecasts $(h=12)$ in column (5). As already noted, the number of observations decreases as the horizon lengthens. To visualize the impact of surprises in the federal funds rate decision on the term structure of the dispersion of inflation expectations, we also plot the coefficient magnitudes along with their confidence intervals in Figure 5.

The results in column (1) indicate that a 100-basis point surprise in the federal funds rate leads, on average, to an increase of 96 basis points in the dispersion of inflation expectations for the month that just went by. Since horizon $h=-\epsilon$ is backward looking (i.e., refers to a month that already finished), the change

\footnotetext{
${ }^{8}$ Uncertainty remains about the effects of policy actions.

${ }^{9}$ Nakamura and Steinsson (2018) refer to this revealed information as "Fed informational effects".
} 
in dispersion does not reflect revised views on future actions by the Fed. In this sense, the estimate for such horizon allows us to isolate the effect of the information that is revealed by the central bank's action (or inaction) on inflation expectation disagreement. Our results suggest that the information conveyed in the policy surprise leads some agents to revise their estimates in a way that leads to a less-coordinated view.

Columns (2) to (5) report the effect of federal funds rate surprises on the dispersion of inflation expectations at the three-, six-, nine-, and 12-month ahead horizons. Since all these horizons are forward looking, changes in analysts' inflation forecasts may reflect the effect of the information that is revealed by the central bank's decision as well as their revised views about future actions by the Fed. The results in columns (2) to (4) indicate that the effect of monetary surprises on the dispersion of inflation forecasts is still positive and significant up to nine months after the Fed announcement. The effect, however, tends to die out out over farther horizons. While the effect of policy surprises one year after the Fed announcement is still positive, it is not statistically different from zero, as shown in column (5).

We then test whether oTheaaur results hold to excluding different events covered by the sample period. In particular, we alternatively drop the period of the Global Financial Crisis (July 2008-December 2009), the entire span over which the Fed hit the zero lower bound (January 2010-December 2014), and the period featuring the largest surprises associated to the monetary policy normalization. As shown in Table 2, the exclusion of these events does not seem to affect our findings. The results are in fact comparable to the ones of the baseline estimations. If anything, the significance of the estimates is somewhat weaker when the period of the Global Financial Crisis is dropped, reflecting the fact that the largest shock get excluded from the sample.

In sum, our results indicate that monetary policy surprises lead to an increase in analysts' disagreement about inflation prospects over the next nine months - a horizon shorter than the lag with which monetary policy is believed to affect prices - but have no effect on disagreement at longer horizons. ${ }^{10}$ Moreover, the effect is stronger for the backward-looking horizon, that we interpret as the informational effect from the central bank's decision.

\subsection{Narrower Time Windows}

Our identification strategy is based on the assumption that all relevant information that the analysts receive before the Fed's meeting is reflected in their latest forecast re-submission. Yet, one concern with this strategy is that analysts may incur fixed costs and decide not to re-submit despite receiving relevant information. In that case, the difference between the Fed's decision and the projection that the analyst had reported does not capture the extent of surprise in the policy decision. Similarly, the change in inflation forecast between the pre- and post-meeting submissions cannot be entirely attributed to the surprise. This would invalidate the identifying assumption and could bias our estimates.

A second concern that analysts do not submit their revised inflation projection immediately after the Fed's meeting. In our baseline setup, we use submissions up to 30 days following the meeting to assess their revised inflation forecasts. But as the lag between the Fed's meeting and the analyst re-submission increases, the revised forecast may reflect not only the effect of the Fed's action but also other developments that happened in-between.

\footnotetext{
${ }^{10}$ Romer and Romer (2004) and Gertler and Karadi (2015) are two heavily cited papers presenting impulse responses of monetary policy shocks on prices. Both papers show that it takes about two years for monetary policy to affect prices. Ramey (2016), however, shows that the estimates vary considerably when the technique and sample, among others, change.
} 
Table 2: Effects of Federal Funds Rate Surprises on Inflation Expectation Dispersion (Percentage points)

\begin{tabular}{|c|c|c|c|c|c|}
\hline & $\begin{array}{c}\text { (1) } \\
\text { Past }\end{array}$ & $\begin{array}{c}(2) \\
3 \text { months } \\
\text { ahead }\end{array}$ & $\begin{array}{c}(3) \\
6 \text { months } \\
\text { ahead }\end{array}$ & $\begin{array}{c}(4) \\
9 \text { months } \\
\text { ahead }\end{array}$ & $\begin{array}{c}(5) \\
12 \text { months } \\
\text { ahead }\end{array}$ \\
\hline \multicolumn{6}{|l|}{ Baseline } \\
\hline Surprises in Fed decision & $\begin{array}{c}0.965^{* * *} \\
(0.126)\end{array}$ & $\begin{array}{c}0.536^{* *} \\
(0.223)\end{array}$ & $\begin{array}{c}0.688^{* * * *} \\
(0.242)\end{array}$ & $\begin{array}{c}0.611^{* *} \\
(0.264)\end{array}$ & $\begin{array}{c}0.061 \\
(0.221)\end{array}$ \\
\hline Observations & 2,263 & 1,390 & 1,356 & 1,294 & 1,175 \\
\hline Analysts & 127 & 62 & 61 & 60 & 58 \\
\hline$R$-squared & 0.061 & 0.008 & 0.011 & 0.008 & 0.000 \\
\hline \multicolumn{6}{|c|}{ Excluding the Global Financial Crisis } \\
\hline Surprises in Fed decision & $\begin{array}{c}1.046^{* * *} \\
(0.174)\end{array}$ & $\begin{array}{c}0.576 \\
(0.369)\end{array}$ & $\begin{array}{c}0.863^{* *} \\
(0.431)\end{array}$ & $\begin{array}{c}0.869^{*} \\
(0.506)\end{array}$ & $\begin{array}{c}0.044 \\
(0.361)\end{array}$ \\
\hline Observations & 2,166 & 1,338 & 1,304 & 1,245 & 1,130 \\
\hline Analysts & 125 & 62 & 61 & 60 & 58 \\
\hline$R$-squared & 0.057 & 0.006 & 0.010 & 0.011 & 0.000 \\
\hline \multicolumn{6}{|c|}{ Excluding zero lower bound period } \\
\hline Surprises in Fed decision & $\begin{array}{c}0.946^{* * *} \\
(0.123)\end{array}$ & $\begin{array}{c}0.488^{* *} \\
(0.236)\end{array}$ & $\begin{array}{c}0.648^{* *} \\
(0.274)\end{array}$ & $\begin{array}{c}0.620^{* *} \\
(0.249)\end{array}$ & $\begin{array}{c}0.119 \\
(0.226)\end{array}$ \\
\hline Observations & 1,538 & 1,005 & 972 & 916 & 817 \\
\hline Analysts & 118 & 58 & 58 & 56 & 54 \\
\hline$R$-squared & 0.070 & 0.008 & 0.012 & 0.012 & 0.000 \\
\hline \multicolumn{6}{|c|}{ Excluding monetary policy normalization } \\
\hline Surprises in Fed decision & $\begin{array}{c}1.159^{* * * *} \\
(0.164)\end{array}$ & $\begin{array}{c}0.790^{* * *} \\
(0.267)\end{array}$ & $\begin{array}{c}0.750^{* * *} \\
(0.278)\end{array}$ & $\begin{array}{c}1.048^{* * *} \\
(0.343)\end{array}$ & $\begin{array}{c}0.377 \\
(0.263)\end{array}$ \\
\hline Observations & 2,008 & 1,208 & 1,183 & 1,117 & 1,008 \\
\hline Analysts & 124 & 61 & 60 & 59 & 57 \\
\hline$R$-squared & 0.073 & 0.014 & 0.012 & 0.020 & 0.003 \\
\hline
\end{tabular}

Source: Authors' calculations.

Notes: All regressions include analyst fixed effects. Heteroskedasticity and autocorrelation consistent standard errors in parentheses. ${ }^{* * *} p<0.01,{ }^{* *} p<0.05,{ }^{*} p<0.1$. 
Figure 5: Effects of Monetary Policy Surprises on the Term Structure of Inflation Expectation Dispersion (Percentage points)

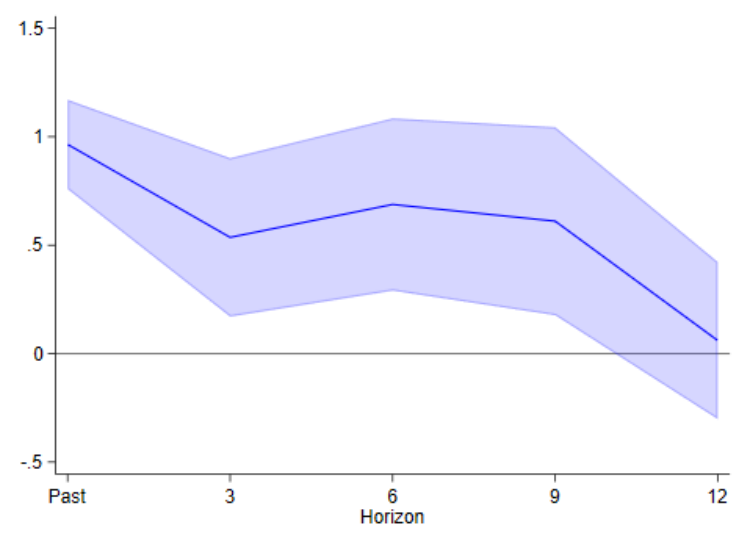

Source: Bloomberg and authors' calculations.

Notes: The line denotes the magnitude of the coefficient of surprise in the central bank decision at different horizons, and the shaded area denotes the 90 percent confidence interval constructed with standard errors clustered at the analyst level. The $\mathrm{x}$-axis denotes the forecast horizon in months, where "past" corresponds to the month that just went by.

To address these concern, we sequentially reduce the time windows around the policy meetings over which we retrieve the analysts forecasts. We reduce both the pre-meeting window (from a maximum of 45 days to a maximum of 5 days) and the post-meeting window (from a maximum of 30 days to a maximum of 10 days). This set of robustness exercises inevitably reduces the number of observations. Figure 6 reports the magnitude of the coefficient along with the confidence interval for all possible combinations of time windows used to compute the policy rate surprises and the dispersion of inflation expectations.

The results show that our earlier finding for the backward-looking horizon is robust to the size of the windows. That is, the point estimate is always statistically significant for $h=-\epsilon$, ranging between 48 and 110 basis points. The estimates for horizons $h=3$ and $h=6$ remain positive and significant for most estimations, or indistinguishable from zero. Finally, the effect of policy surprises on the dispersion of inflation forecasts at horizons $h=9$ and $h=12$ turn negative and statistically significant when the pre-meeting window is shrunk to five days and the post-meeting window is reduced to 15 or 10 days. In sum, monetary policy surprises generally lead to more dispersion in inflation expectations at short horizons and have no effect or reduce dispersion over longer horizons.

In an additional robustness exercise, we hold the maximum of the dispersion at a maximum of 30 days and reduce the surprise window further by replacing the surprise measure in equation (3) with the "federal funds rate shocks" constructed in Nakamura and Steinsson (2018). The latter consists of unexpected changes in interest rates in a 30-minute window surrounding the federal funds rate announcements in the United States. Such a small time window ensures that the role played by confounding factors is critically minimized or non-existent. It also has the advantage of not being limited to changes in the federal funds rate, but incorporating information about the future path of interest rates in response to Fed announcements. For the purposes of estimating analyst-level regressions, however, such a variable is less satisfactory because it is constructed from data on futures and therefore lacks cross-sectional variation. In other words, by using it, we are imposing the same surprise across all analysts. 
Figure 6: Alternative Pre- and Post-Meeting Windows

(Percentage points)

(a) Pre-meeting window: 45 days

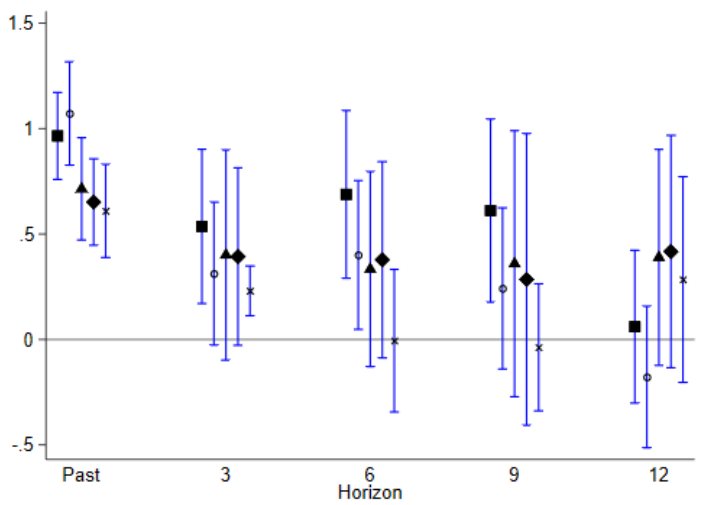

(c) Pre-meeting window: 20 days

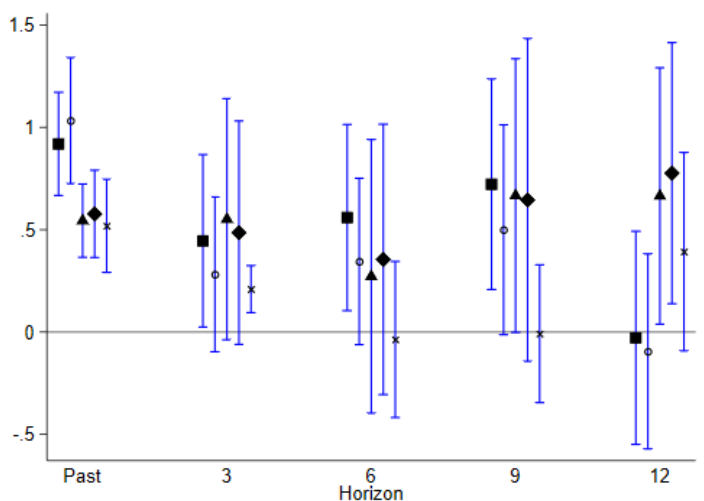

(b) Pre-meeting window: 30 days

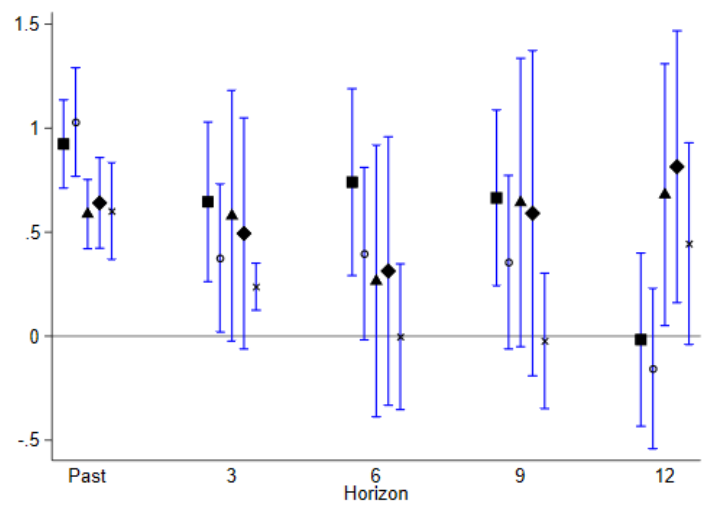

(d) Pre-meeting window: 10 days

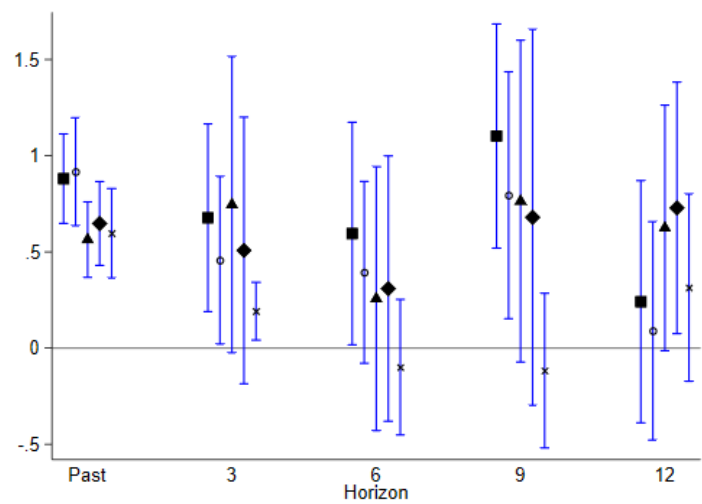

(e) Pre-meeting window: 5 days

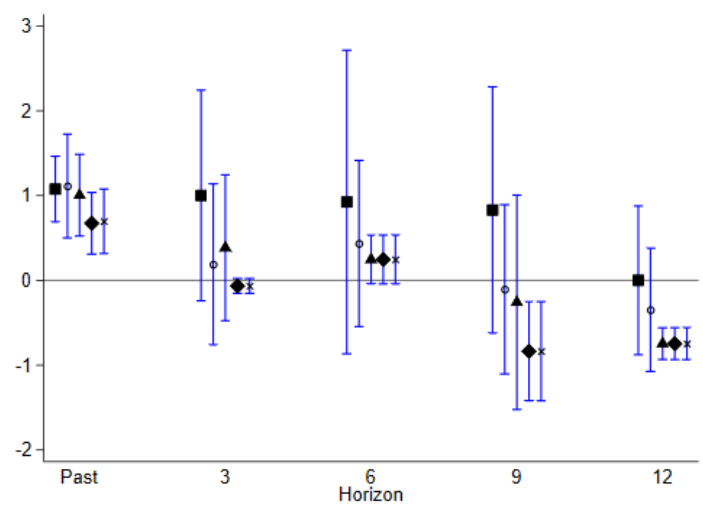

Source: Bloomberg and authors' calculations.

Notes: Each panel reports the results based on alternative pre-meeting windows for the monetary policy surprise calculation. Square, (circle), [triangle], rhombus, and /cross/ markers denote point estimates for the post-meeting window of 30, (25), [20], 15, and /10/ days over different horizons, and the vertical lines denote the 90 percent confidence intervals constructed with standard errors clustered at the analyst level. The x-axis denotes the forecast horizon in months, where "past" corresponds to the the month that just went by. 
We find a strong positive and significant effect of the federal funds rate shocks on inflation expectation dispersion. The results in the top panel of Table 3 indicate that a 100-basis point shock in the federal funds rate leads to a 157 basis points increase in inflation expectation dispersion for the month that just finished $(h=-\epsilon)$. This effect becomes even larger at longer horizons and remains statistically significant, with the largest impact registered for horizon $h=9$, at 220 basis points.

We then replace the federal funds rate shocks with the "policy news shocks", also from Nakamura and Steinsson (2018). These correspond to the first principal component of the unanticipated changes in the Fed funds rate immediately following the FOMC meeting, the expected Fed funds rate immediately following the next FOMC meeting, and expected three-month eurodollar interest rates at horizons of two, three, and four quarters. The results in the bottom panel Table 3 report somewhat larger estimates compared to the ones associated to the "federal funds rate shocks "- possibly reflecting the impact of forward guidance - with the exceptions of $h=-\epsilon$, where the effect is smaller by 24 basis points, and $h=12$, where the effect is not statistically distinguishable from zero. While these exercises use aggregate instead of analyst-specific surprises, the results provide reassuring evidence of the robustness of our baseline findings.

Table 3: Effects of High-Frequency Monetary Policy Shocks on Inflation Expectation Dispersion (Percentage points)

\begin{tabular}{|c|c|c|c|c|c|}
\hline & $\begin{array}{c}(1) \\
\text { Past }\end{array}$ & $\begin{array}{c}(2) \\
3 \text { months } \\
\text { ahead }\end{array}$ & $\begin{array}{c}(3) \\
6 \text { months } \\
\text { ahead }\end{array}$ & $\begin{array}{c}(4) \\
9 \text { months } \\
\text { ahead }\end{array}$ & $\begin{array}{c}(5) \\
12 \text { months } \\
\text { ahead }\end{array}$ \\
\hline Federal funds rate shock & $\begin{array}{c}1.567^{* * *} \\
(0.250)\end{array}$ & $\begin{array}{c}1.994^{* * *} \\
(0.605)\end{array}$ & $\begin{array}{c}2.201^{* * *} \\
(0.766)\end{array}$ & $\begin{array}{c}2.524^{* * *} \\
(0.719)\end{array}$ & $\begin{array}{c}1.865^{* * *} \\
(0.675)\end{array}$ \\
\hline $\begin{array}{l}\text { Observations } \\
\text { Analysts } \\
R \text {-squared }\end{array}$ & $\begin{array}{c}2,088 \\
106 \\
0.024\end{array}$ & $\begin{array}{c}1,308 \\
50 \\
0.010\end{array}$ & $\begin{array}{c}1,278 \\
50 \\
0.011\end{array}$ & $\begin{array}{c}1,223 \\
50 \\
0.011\end{array}$ & $\begin{array}{c}1,115 \\
49 \\
0.006\end{array}$ \\
\hline Policy news shock & $\begin{array}{c}1.335^{* * *} \\
(0.253)\end{array}$ & $\begin{array}{l}2.258^{*} \\
(1.148)\end{array}$ & $\begin{array}{c}2.578^{* * *} \\
(0.790)\end{array}$ & $\begin{array}{c}3.148^{* * *} \\
(1.140)\end{array}$ & $\begin{array}{c}1.888 \\
(1.347)\end{array}$ \\
\hline $\begin{array}{l}\text { Observations } \\
\text { Analysts } \\
R \text {-squared }\end{array}$ & $\begin{array}{c}2,088 \\
106 \\
0.009\end{array}$ & $\begin{array}{l}1,308 \\
50 \\
0.005\end{array}$ & $\begin{array}{c}1,278 \\
50 \\
0.006\end{array}$ & $\begin{array}{c}1,223 \\
50 \\
0.008\end{array}$ & $\begin{array}{c}1,115 \\
49 \\
0.003\end{array}$ \\
\hline
\end{tabular}

Source: Authors' calculations.

Notes: All regressions include analyst fixed effects. Heteroskedasticity and autocorrelation consistent standard errors in parentheses. ${ }^{* * *} p<0.01,{ }^{* *} p<0.05,{ }^{*} p<0.1$.

\subsection{The Role of Market Surprises}

Our baseline specification focuses on policy surprises at the analyst level, however agents may just imitate other agents (i.e., the "market") at the time of the submission of their policy rate forecast. This may occur, for example, if the costs associated to preparing the forecast are high or if the analyst is not confident enough in her model to predict the federal funds rate.

To investigate if it is individual surprises or market surprises that lead to more inflation expectation dispersion, we augment our baseline specification as follows:

$$
d_{i, t+h \mid t}^{\pi^{e}}=\beta s_{i, t-1+\gamma \mid t-1}^{p^{e}}+\theta m s_{i, t-1+\gamma \mid t-1}^{p^{e}}+\phi_{i}+\mu_{i, t+h}
$$


where $m s_{i, t-1+\gamma \mid t-1}^{p^{e}}$ denotes the market surprises, calculated as the absolute value of the deviation of the consensus forecast of the federal funds rate (calculated as the mean across all analysts excluding the individual's forecast over the 30 days prior to the announcement day) from the actual federal funds rate:

$$
m s_{i, t-1+\gamma \mid t-1}^{p^{e}}=\left|\frac{1}{N-1}\left(\sum_{i=1}^{N} p_{i, t-1+\gamma \mid t-1}^{e}-p_{i, t-1+\gamma \mid t-1}^{e}\right)-p_{t-1+\gamma \mid t-1+\gamma}^{r}\right|
$$

with $\gamma<45$ days.

Table 4 reports the results of the estimation of equation (4). At horizon $h=-\epsilon$, the effect is positive and significant both for the individual surprises and for the market surprises. A 100-basis point individual (market) surprise in the federal funds rate leads to a higher inflation expectation dispersion by 53 (68) basis points. For the other horizons, the coefficients are not always significant for individual surprises, but they are generally positive.

Table 4: Effects of Individual and Market Surprises on Inflation Expectation Dispersion (Percentage points)

\begin{tabular}{|c|c|c|c|c|c|}
\hline & $\begin{array}{l}(1) \\
\text { Past }\end{array}$ & $\begin{array}{c}(2) \\
3 \text { months } \\
\text { ahead }\end{array}$ & $\begin{array}{c}(3) \\
6 \text { months } \\
\text { ahead }\end{array}$ & $\begin{array}{c}(4) \\
9 \text { months } \\
\text { ahead }\end{array}$ & $\begin{array}{c}(5) \\
12 \text { months } \\
\text { ahead }\end{array}$ \\
\hline Individual surprises & $\begin{array}{c}0.526^{* * *} \\
(0.124)\end{array}$ & $\begin{array}{l}0.400^{*} \\
(0.224)\end{array}$ & $\begin{array}{c}0.407 \\
(0.247)\end{array}$ & $\begin{array}{c}0.316 \\
(0.267)\end{array}$ & $\begin{array}{l}-0.336 \\
(0.305)\end{array}$ \\
\hline Market surprises & $\begin{array}{c}0.680^{* * *} \\
(0.104)\end{array}$ & $\begin{array}{c}0.359 \\
(0.240)\end{array}$ & $\begin{array}{l}0.524^{*} \\
(0.298)\end{array}$ & $\begin{array}{c}0.578^{* *} \\
(0.284)\end{array}$ & $\begin{array}{l}0.723^{*} \\
(0.381)\end{array}$ \\
\hline Wald test $p$-value & 0.407 & 0.913 & 0.794 & 0.569 & 0.100 \\
\hline Observations & 2,262 & 1,347 & 1,356 & 1,294 & 1,175 \\
\hline Analysts & 126 & 61 & 61 & 60 & 58 \\
\hline$R$-squared & 0.094 & 0.013 & 0.018 & 0.016 & 0.012 \\
\hline
\end{tabular}

Source: Authors' calculations.

Notes: All regressions include analyst fixed effects. Heteroskedasticity and autocorrelation consistent standard errors in parentheses. ${ }^{* * *} p<0.01,{ }^{* *} p<0.05,{ }^{*} p<0.1$.

In another exercise, we use the measure of Nakamura and Steinsson (2018) - which we call NS-based market surprises - to replace the market surprises in equation (4). The results in the top panel of Table 5 indicate that when market surprises are proxied by the federal funds rate shocks, both individual and market surprises lead to higher inflation expectation dispersion; the results in the bottom panel suggest when market surprises are proxied by the policy news shocks, only the individual surprises come out significant. In both cases, the magnitude of the coefficient on the individual surprises is similar to the one of the baseline specification. At intermediate horizons, the coefficients are always positive, but often not significant. At $h=12$, the only significant coefficient is the one on the federal funds rate shock, while the coefficients on individual surprises turn negative, but not significant. We conclude that individual surprises unequivocally lead to a larger disagreement about inflation projections above and beyond the surprises of the market.

\subsection{Deviations From the Inflation Target}

In a final exercise we change the definition of the dependant variable. In particular, we substitute the measure of dispersion in inflation forecasts across analysts with the distance between each analyst's forecast and the 
Table 5: Effects of Individual and NS-Based Market Surprises on Inflation Expectation Dispersion (Percentage points)

\begin{tabular}{|c|c|c|c|c|c|}
\hline & $\begin{array}{l}(1) \\
\text { Past }\end{array}$ & $\begin{array}{c}(2) \\
3 \text { months } \\
\text { ahead }\end{array}$ & $\begin{array}{c}(3) \\
6 \text { months } \\
\text { ahead }\end{array}$ & $\begin{array}{c}(4) \\
9 \text { months } \\
\text { ahead }\end{array}$ & $\begin{array}{c}(5) \\
12 \text { months } \\
\text { ahead }\end{array}$ \\
\hline Individual surprises & $\begin{array}{c}0.887^{* * *} * \\
(0.145)\end{array}$ & $\begin{array}{c}0.376 \\
(0.285)\end{array}$ & $\begin{array}{c}0.487 \\
(0.332)\end{array}$ & $\begin{array}{c}0.404 \\
(0.332)\end{array}$ & $\begin{array}{l}-0.184 \\
(0.279)\end{array}$ \\
\hline Federal funds rate shock & $\begin{array}{c}0.656^{* *} \\
(0.257)\end{array}$ & $\begin{array}{c}1.483 \\
(0.923)\end{array}$ & $\begin{array}{c}1.554 \\
(1.088)\end{array}$ & $\begin{array}{l}1.907^{*} \\
(1.068)\end{array}$ & $\begin{array}{c}2.161^{* *} \\
(0.916)\end{array}$ \\
\hline Wald test $p$-value & 0.495 & 0.345 & 0.429 & 0.266 & 0.044 \\
\hline Observations & 2,088 & 1,308 & 1,278 & 1,223 & 1,115 \\
\hline Analysts & 106 & 50 & 50 & 50 & 49 \\
\hline$R$-squared & 0.066 & 0.013 & 0.015 & 0.014 & 0.007 \\
\hline Individual surprise & $\begin{array}{c}0.918^{* * *} * \\
(0.147)\end{array}$ & $\begin{array}{l}0.473^{*} \\
(0.270)\end{array}$ & $\begin{array}{c}0.590^{* *} \\
(0.278)\end{array}$ & $\begin{array}{l}0.511^{*} \\
(0.298)\end{array}$ & $\begin{array}{l}-0.016 \\
(0.255)\end{array}$ \\
\hline Policy news shock & $\begin{array}{c}0.171 \\
(0.281)\end{array}$ & $\begin{array}{c}1.549 \\
(1.466)\end{array}$ & $\begin{array}{c}1.811^{*} \\
(1.025)\end{array}$ & $\begin{array}{l}2.428^{*} \\
(1.438)\end{array}$ & $\begin{array}{c}2.003 \\
(1.537)\end{array}$ \\
\hline Wald test $p$-value & 0.018 & 0.506 & 0.331 & 0.264 & 0.278 \\
\hline Observations & 2,088 & 1,308 & 1,278 & 1,223 & 1,115 \\
\hline Analysts & 106 & 50 & 50 & 50 & 49 \\
\hline$R$-squared & 0.062 & 0.011 & 0.013 & 0.013 & 0.003 \\
\hline
\end{tabular}

Source: Authors' calculations.

Notes: All regressions include analyst fixed effects. Heteroskedasticity and autocorrelation consistent standard errors in parentheses. ${ }^{* * *} p<0.01,{ }^{* *} p<0.05,{ }^{*} p<0.1$.

inflation target of the central bank, $d a_{i, t+h \mid t}^{\pi^{e}}$, which is another way of proxing the extent of anchoring of inflation expectations ${ }^{11}$ :

$$
d a_{i, t+h \mid t}^{\pi^{e}}=\left|\pi_{i, t+h \mid t}^{e}-\pi_{t+h}^{*}\right|
$$

where $\pi^{*}$ is the inflation target.

In the United States, the inflation target was not formally announced until 2012. However, in a FOMC meeting in 1996, former Fed Chairman Greenspan summarized the consensus mentioning a target of 2 percent. In January 2012, the FOMC issued a statement regarding its longer-run goals and monetary policy strategy in which it publicly noted that an inflation at the rate of 2 percent - measured with the personal consumption expenditure (PCE) index - is "most consistent over the longer run with the Fed's statutory mandate". To compute equation (6), we rely on both CPI (until January 2012) and PCE (after January 2012), and use a target of 2 percent over the sample period. ${ }^{12}$

The results in Table 6 indicate that a 100-basis point surprise in the federal funds rate decision leads, for $h=-\epsilon$, to an increase in the deviation of CPI (PCE) inflation estimates from the target of 82 (162) basis points. ${ }^{13}$ The results at other horizons are mixed: a monetary surprise leads to larger deviations of projected CPI from the target at all intermediate horizons, but this is only the case at $h=3$ when we use PCE inflation expectations. At $h=12$, surprises in the federal funds rate decision do not have any impact.

\footnotetext{
${ }^{11}$ See Bems et al. (2018) for a discussion of the measurement of inflation expectation anchoring.

${ }^{12}$ Data on PCE inflation expectations are available starting in May 2004 for horizon $h=-\epsilon$ and December 2014 for horizon $h=\{3,6,9,12\}$.

${ }^{13}$ Running the regressions of the metric in equation (6) constructed with CPI using the entire sample (i.e., pre- and postJanuary 2012) returns similar results.
} 
Table 6: Effects of Federal Funds Rate Surprises on Inflation Expectation Anchoring (Percentage points)

\begin{tabular}{|c|c|c|c|c|c|}
\hline & $\begin{array}{c}(1) \\
\text { Past }\end{array}$ & $\begin{array}{c}(2) \\
3 \text { months } \\
\text { ahead }\end{array}$ & $\begin{array}{c}(3) \\
6 \text { months } \\
\text { ahead }\end{array}$ & $\begin{array}{c}(4) \\
9 \text { months } \\
\text { ahead }\end{array}$ & $\begin{array}{c}(5) \\
12 \text { months } \\
\text { ahead }\end{array}$ \\
\hline \multicolumn{6}{|c|}{ Anchoring based on CPI inflation } \\
\hline Surprises in Fed decision & $\begin{array}{c}0.824^{* *} \\
(0.347)\end{array}$ & $\begin{array}{c}1.243 \\
(0.759)\end{array}$ & $\begin{array}{c}1.791^{* *} \\
(0.862)\end{array}$ & $\begin{array}{c}1.924^{* *} \\
(0.775)\end{array}$ & $\begin{array}{c}0.180 \\
(0.334)\end{array}$ \\
\hline Observations & 858 & 380 & 380 & 367 & 330 \\
\hline Analysts & 83 & 36 & 36 & 34 & 33 \\
\hline$R$-squared & 0.004 & 0.010 & 0.021 & 0.033 & 0.001 \\
\hline \multicolumn{6}{|c|}{ Anchoring based on PCE inflation } \\
\hline Surprise in Fed decision & $\begin{array}{c}1.617^{* * * *} \\
(0.229)\end{array}$ & $\begin{array}{c}1.099 * * \\
(0.792)\end{array}$ & $\begin{array}{l}-1.209 \\
(0.725)\end{array}$ & $\begin{array}{l}-0.236 \\
(0.587)\end{array}$ & $\begin{array}{l}-0.209 \\
(0.334)\end{array}$ \\
\hline Observations & 1,430 & 376 & 358 & 334 & 307 \\
\hline Analysts & 93 & 30 & 28 & 28 & 28 \\
\hline$R$-squared & 0.017 & 0.006 & 0.008 & 0.000 & 0.001 \\
\hline
\end{tabular}

Source: Authors' calculations.

Notes: All regressions include analyst fixed effects. Heteroskedasticity and autocorrelation consistent standard errors in parentheses. ${ }^{* * *} p<0.01,{ }^{* *} p<0.05,{ }^{*} p<0.1$.

\section{A Model of Inflation Expectations Dispersion}

The literature has proposed alternative theoretical frameworks to explain the disagreement in inflation expectations. Mankiw and Reis (2002) argue that information is "sticky" because agents update their information sets infrequently as they incur in fixed costs when they acquire new information. The degree of information stickiness or rigidity, which corresponds to the probability of not acquiring new information each period, generates endogenous disagreement in expectations that in turn affects agents' actions and the resulting equilibrium evolution of the economy. Woodford (2003), Sims (2003), and Mackowiak and Wiederholt (2009) propose models of "noisy" information in which agents continue to update their information set, but they can never fully observe the true state of the economy and they have to form and update their beliefs about the underlying fundamentals heterogeneously via signal extraction. Lorenzoni (2009) shows that if information is "dispersed", agents take longer to learn about long-run productivity and this generates heterogeneity in beliefs. ${ }^{14}$

To rationalize our empirical results, we present a partial equilibrium model with rational expectations and information rigidities in the tradition of Mankiw and Reis (2002). In this setting, the costs of acquiring and processing information and of reoptimizing lead agents to update their information sets and their expectations infrequently. As a result, in each period only a fraction of the population update their views on the current

\footnotetext{
${ }^{14}$ Relatedly, Bordalo et al. (2018) propose a model of "diagnostic expectations" in which agents form expectation based on the representativeness heuristic, i.e. overweighting the likelihood of future outcomes that become more likely in light of the current news. Bordalo et al. (2020) show that the reason for the difference between forecasters' overreaction to individual news and consensus under-reaction to average forecaster news is that each individual forecaster reacts to his own signal and not to the ones observed by the other forecasters. Since all signals are informative and on average correct about the state, the average forecast under-reacts to the average information.
} 
state of the economy and determine their optimal actions. The rest of the population continues to act according to their pre-existing plans based on old information. Information is therefore rigid or sticky, with the degree of information rigidity or stickiness equals the likelihood of not acquiring new information in each period.

We assume a closed economy in which a representative agent at time $t$ consumes a final good in quantity $C_{t}$, which is a composite of a continuum of differentiated intermediate consumption goods $c_{t}^{j}$

$$
C_{t}=\left[\int_{0}^{1}\left(c_{t}^{j}\right)^{\frac{\gamma-1}{\gamma}} d j\right]^{\frac{\gamma}{\gamma-1}}
$$

where $\gamma$ denotes the elasticity of substitution between intermediate goods.

Since we do not model the optimization problem of the representative consumer and we abstract from capital accumulation and government spending, total demand in this economy is equal to $C_{t}$. We assume that such demand depends positively on the level of the aggregate productivity in the economy $z_{t}$ - through the impact of such productivity on the households' labor income and returns - and negatively on the level of the interest rate in the economy $i_{t}$-that determines the inter-temporal opportunity cost of consumption, so that we have $C_{t}\left(z_{t}, i_{t}\right)$ with $C_{z}=\frac{\partial C_{t}\left(z_{t}, i_{t}\right)}{\partial z_{t}}>0$ and $C_{i}=\frac{\partial C_{t}\left(z_{t}, i_{t}\right)}{\partial i_{t}}<0$.

We define the aggregate state in the economy as $s_{t}=\left(z_{t}, i_{t}\right)$ and we assume that the aggregate variable have the following stochastic processes

$$
\begin{aligned}
z_{t} & =\left(1-\rho^{z}\right) \bar{z}+\rho^{z} z_{t-1}+\varepsilon_{t}^{z} \\
i_{t} & =\bar{i}+\zeta_{t}^{i} \\
\zeta_{t}^{i} & =\rho^{i} \zeta_{t-1}^{i}+\varepsilon_{t}^{i}
\end{aligned}
$$

where $\varepsilon_{t}^{z} \sim N\left(0, \sigma_{z}^{2}\right)$ and $\varepsilon_{t}^{i} \sim N\left(0, \sigma_{i}^{2}\right)$.

On the production side of the economy, there is a continuum of monopolistic firms $j$ (owned by the consumers) that produce differentiated goods $y_{t}^{j}$. Firms' individual profits are a function of the aggregate productivity in the economy $z_{t}$, the interest rate in the economy $i_{t}$, and an idiosyncratic productivity shock to each firm $\vartheta_{t}^{j}$, and can be written as $^{15}$

$$
\Pi_{t}^{j}=P_{t}^{j} Y_{t}^{j}-m c_{t}^{j} Y_{t}^{j}
$$

where $m c_{t}^{j}$ is the marginal cost, which is a function of both the aggregate state of the economy $s_{t}$ and the idiosyncratic productivity shock $\vartheta_{t}^{j}$, so that $m c_{t}^{j}=\vartheta_{t}^{j}\left(\alpha_{1} z_{t}+\alpha_{2} i_{t}\right)$ with $\alpha_{1}<0$ and $\alpha_{2}>0$. We assume that the distribution of idiosyncratic shocks across firms is time-invariant.

Since firms are monopolistic, each of them faces the market demand for the good they produce

$$
Y_{t}^{j}=\left(\frac{P_{t}^{j}}{P_{t}}\right)^{-\gamma} C_{t}=c_{t}^{j}
$$

\footnotetext{
${ }^{15}$ Higher total factor productivity in the economy $z_{t}$ allows individual firms to produce more efficiently. Higher interest rates increase the costs of production of the firms by either raising the opportunity cost of capital accumulation or by raising production costs when firms need to borrow in advance to start producing. In this paper, however, we do not model these mechanisms.
} 
where the price index for the economy is

$$
P_{t}=\left[\int_{0}^{1}\left(P_{t}^{j}\right)^{1-\gamma} d j\right]^{\frac{1}{1-\gamma}}
$$

The optimization problem of the firms consists of maximizing the value of the firm

$$
V_{t}^{j}=\mathbb{E}_{t}\left[\sum_{t+\tau}^{\infty} R_{t+\tau \mid t}\left(\Pi_{t}^{j}\right)\right]
$$

where $R_{t+\tau \mid t}$ is the discount factor of the firm (to be defined later).

To decide the optimal production and pricing strategy, each firm needs to produce a forecast for aggregate inflation. The process leading to the formation of inflation expectations is a fundamental input to determine the equilibrium outcomes of the model. In what follows, we compare four characterizations of the mechanisms underlying the formation of inflation expectations. These are all based on rational expectations, but differ in the assumptions about information rigidity: ${ }^{16,17}$

- Full information (i.e., no stickiness).

- Constant degree of information stickiness.

- Degree of information stickiness depending on the realizations of the aggregate states of the economy, falling when the realizations of the state variables are farther away from their mean realizations.

- Degree of information stickiness varying across firms, lower for those with idiosyncratic shocks to their marginal costs farther away from the mean realization of those shocks.

\subsection{Full Information}

Under full information, the maximization of the value of the firm is equivalent to maximizing period-by-period profits. Thus, the first order condition of the firm is

$$
\left(\frac{\partial P_{t}^{j}}{\partial Y_{t}^{j}}\right) Y_{t}^{j}+P_{t}^{j}-m c_{t}^{j}=0
$$

which implies that

$$
P_{t}^{j}=\frac{\gamma}{\gamma-1} m c_{t}^{j}
$$

Marginal costs differ across firms due to the idiosyncratic shocks to these costs. As a result, prices across firms also differ and there is price dispersion in the economy. This can be shown by substituting equation (16) for individual prices of the firms into equation (13) for the price index of the economy

$$
\begin{aligned}
P_{t} & =\frac{\gamma}{\gamma-1}\left(\alpha_{1} z_{t}+\alpha_{2} i_{t}\right)\left[\int_{0}^{1}\left(\vartheta_{t}^{j}\right)^{1-\gamma} d j\right]^{\frac{1}{1-\gamma}} \\
& =\frac{\gamma}{\gamma-1}\left(\alpha_{1} z_{t}+\alpha_{2} i_{t}\right)\left(\mathbb{E}\left[\vartheta^{1-\gamma}\right]\right)^{\frac{1}{1-\gamma}}
\end{aligned}
$$

\footnotetext{
${ }^{16}$ In what follows, we use interchangeably firm and forecaster, and rigidity and stickiness.

${ }^{17}$ Appendix A reports the parameter values.
} 
which suggests that the price level of the economy is a function only of the aggregate state of the economy $s_{t}$. In fact, the idiosyncratic shocks to the marginal costs of the firms do not alter the determination of the economy's price level, rather only their mean realization $\left(\mathbb{E}_{t}\left[\vartheta^{1-\gamma}\right]\right)^{\frac{1}{1-\gamma}}$ does.

The price level expectations for the next period are

$$
\mathbb{E}_{t}\left[P_{t+1}\right]=\frac{\gamma}{\gamma-1}\left(\alpha_{1} \mathbb{E}_{t}\left[z_{t+1} \mid z_{t}\right]+\alpha_{2} \mathbb{E}_{t}\left[i_{t+1} \mid i_{t}\right]\right)\left(\mathbb{E}\left[\vartheta^{1-\gamma}\right]\right)^{\frac{1}{1-\gamma}}
$$

Hence, one-period ahead inflation expectations $\mathbb{E}_{t}\left[\pi_{t+1}\right]=\pi_{t+1}^{e}=\mathbb{E}_{t}\left[\frac{P_{t+1}}{P_{t}}\right]$ are

$$
\pi_{t+1}^{e}=\frac{\alpha_{1} \mathbb{E}_{t}\left[z_{t+1} \mid z_{t}\right]+\alpha_{2} \mathbb{E}_{t}\left[i_{t+1} \mid i_{t}\right]}{\alpha_{1} \mathbb{E}_{t}\left[z_{t}\right]+\alpha_{2} \mathbb{E}_{t}\left[i_{t}\right]}
$$

and $\tau$-period ahead inflation expectations are

$$
\pi_{t+\tau}^{e}=\frac{\alpha_{1} \mathbb{E}_{t}\left[z_{t+\tau} \mid z_{t}\right]+\alpha_{2} \mathbb{E}_{t}\left[i_{t+\tau} \mid i_{t}\right]}{\alpha_{1} \mathbb{E}_{t}\left[z_{t+\tau-1} \mid z_{t}\right]+\alpha_{2} \mathbb{E}_{t}\left[i_{t+\tau-1} \mid i_{t}\right]}
$$

where $\mathbb{E}_{t}\left(z_{t+\tau} \mid z_{t}\right)=\mathbb{E}_{t}\left(z_{t+\tau} \mid z_{t+\tau-1}\right) \mathbb{E}_{t}\left(z_{t+\tau-1} \mid z_{t+\tau-2}\right) \ldots \mathbb{E}_{t}\left(z_{t+1} \mid z_{t}\right)$ and $\mathbb{E}_{t}\left(i_{t+\tau} \mid i_{t}\right)=\mathbb{E}_{t}\left(i_{t+\tau} \mid i_{t+\tau-1}\right) \mathbb{E}_{t}\left(i_{t+\tau-1} \mid i_{t+\tau-2}\right) \ldots \mathbb{E}_{t}\left(i_{t+1} \mid i_{t}\right)$.

Thus, in absence of information rigidity, heterogeneity across firms leads to dispersion of prices. However, since all firms have full information and know the stochastic process for the aggregate state of the economy, as well as the time-invariant distribution of the idiosyncratic shocks, all firms make the same forecast for the aggregate price level $P_{t+\tau}$ at all horizons $t+\tau$. As a result, the dispersion of inflation expectationsdefined as the deviation of the individual forecaster's inflation expectation $\pi_{t+\tau}^{e, j}$ from the consensus forecast $\pi_{t+\tau}^{e}=\int_{0}^{1} \pi_{t+\tau}^{e, j} d j$-is always zero

$$
d_{t+\tau \mid t}=\max \left|\pi_{t+\tau}^{e, j}-\mathbb{E}_{t}\left[\pi_{t+\tau}^{e}\right]\right|=0
$$

We conclude that, even with heterogeneous forecasters, the assumption of rational expectations and full information are not consistent with the existence of inflation expectation dispersion. Hence, models that characterize the expectation formation mechanism in such way cannot be used to explain the patterns observed in the data of the United States.

\subsection{Constant Degree of Information Rigidity}

We now assume that there is some constant degree of information rigidity captured by the parameter $0<$ $\lambda<1$, where $\lambda=0$ corresponds to full information case analyzed in Section 4.1 and $\lambda=1$ corresponds to the case of an economy in which firms never change their expectations. For values of $\lambda$ between 0 and 1 , a random fraction of firms $\lambda$ does not update its information set (i.e., does not observe the realization of the aggregate and idiosyncratic shocks); hence, these firms keep their individual price at the level set in the previous period $P_{t}^{j}=P_{t-1}^{j}$. The reminder of firms, corresponding to fraction $1-\lambda$, update their information set and change prices accordingly, taking into account that with probability $\lambda$ they will not revise the price chosen today.

The objective function of the firms' optimization problem in period $t$ is given by the discounted sum of 
profits over the periods in which the firms are likely to maintain their information set and the price they choose today

$$
\mathbb{E}_{t} \sum_{\tau=0}^{\infty} \lambda^{\tau} R_{t+\tau \mid t}\left(P_{t}^{j} Y_{t+\tau}^{j}-m c_{t+\tau}^{j} Y_{t+\tau}^{j}\right)
$$

The first order condition of firm $j$ with respect to $P_{t}^{j}$ is

$$
E_{t} \sum_{\tau=0}^{\infty} \lambda^{\tau} R_{t+\tau \mid t}\left[\left(\frac{P_{t}^{j}}{P_{t+\tau}}\right)^{-\gamma} C_{t+\tau}-\gamma\left(P_{t}^{j}-m c_{t+\tau}^{j}\right)\left(\frac{P_{t}^{j}}{P_{t+\tau}}\right)^{-\gamma-1} \frac{1}{P_{t+\tau}} C_{t+\tau}\right]=0
$$

and the optimal price is

$$
P_{t}^{j}=\frac{\gamma}{\gamma-1}\left(\frac{\mathbb{E}_{t} \sum_{\tau=0}^{\infty} \lambda^{\tau} R_{t+\tau \mid t}\left(P_{t+\tau}\right)^{\gamma} C_{t+\tau} m c_{t+\tau}^{j}}{\mathbb{E}_{t} \sum_{\tau=0}^{\infty} \lambda^{\tau} R_{t+\tau \mid t}\left(P_{t+\tau}\right)^{\gamma} C_{t+\tau}}\right)
$$

Assuming that the discount factor of the firms is the inter-temporal marginal rate of substitution of consumption of the representative consumer, we define $R_{t+\tau \mid t}$ as

$$
R_{t+\tau \mid t}=\beta^{\tau} \mathbb{E}_{t} \frac{C_{t+\tau}^{-\sigma}}{C_{t}^{-\sigma}}
$$

where $\beta$ is the discount factor of the consumer and $\sigma$ is the coefficient of risk aversion of consumers with preferences that can be represented with a functional form exhibiting constant relative risk aversion (i.e., $\left.u\left(C_{t}\right)=\frac{c^{1-\sigma}}{1-\sigma}\right)$.

Substituting equation (25) into (24), we obtain the following expression for the prices of firm $j$

$$
P_{t}^{j}=\frac{\gamma}{\gamma-1}\left(\frac{\mathbb{E}_{t} \sum_{\tau=0}^{\infty} \lambda^{\tau} \beta^{\tau}\left(P_{t+\tau}\right)^{\gamma}\left(C_{t+\tau}\right)^{1-\sigma} m c_{t+\tau}^{j}}{\mathbb{E}_{t} \sum_{\tau=0}^{\infty} \lambda^{\tau} \beta^{\tau}\left(P_{t+\tau}\right)^{\gamma}\left(C_{t+\tau}\right)^{1-\sigma}}\right)
$$

Aggregating over the prices of all firms that update their information set in period $t$ we obtain

$$
P_{t}^{*}=\frac{\gamma}{\gamma-1}\left[\frac{\mathbb{E}_{t} \sum_{\tau=0}^{\infty} \lambda^{\tau} \beta^{\tau}\left(P_{t+\tau}\right)^{\gamma}\left(C_{t+\tau}\right)^{1-\sigma}\left(\alpha_{1} z_{t+\tau}+\alpha_{2} i_{t+\tau}\right)\left(\mathbb{E}\left[\vartheta^{1-\gamma}\right]\right)^{\frac{1}{1-\gamma}}}{\mathbb{E}_{t} \sum_{\tau=0}^{\infty} \lambda^{\tau} \beta^{\tau}\left(P_{t+\tau}\right)^{\gamma}\left(C_{t+\tau}\right)^{1-\sigma}}\right]
$$

Since a random fraction $\lambda$ of firms keep their prices at the same level than in the previous period, the aggregate price level for the current period can be calculated as a weighted average of the aggregate price in the previous period $P_{t-1}$ and the average price of the firms that update their prices in the current period $P_{t}^{*}$

$$
P_{t}=\lambda P_{t-1}+(1-\lambda) P_{t}^{*}
$$

As in the case with full information, $P_{t}$ only depends on the aggregate state of the economy $s_{t}$ and the mean realization of the idiosyncratic shocks to the marginal costs of the firms. The idiosyncratic shocks themselves do not matter for the determination of the aggregate variables in the economy. Therefore, stickiness in information translates into stickiness in the prices level, and this stickiness in the price level increases with the stickiness in information (i.e., prices will look much more alike to prices in the previous 
period for higher values of $\lambda$ ).

Iterating the expression for the aggregate price level forward we obtain the expected value of the next period price level

$$
\mathbb{E}_{t}\left[P_{t+1}\right]=\lambda P_{t}+(1-\lambda) \mathbb{E}_{t}\left[P_{t+1}^{*}\right]
$$

where

$$
\mathbb{E}_{t}\left[P_{t+1}^{*}\right]=\frac{\gamma}{\gamma-1}\left[\frac{\mathbb{E}_{t} \sum_{\tau=0}^{\infty} \lambda^{\tau} \beta^{\tau}\left(P_{t+\tau+1}\right)^{\gamma}\left(C_{t+\tau+1}\right)^{1-\sigma}\left(\alpha_{1} z_{t+\tau+1}+\alpha_{2} i_{t+\tau+1}\right)\left(\mathbb{E}\left[\vartheta^{1-\gamma}\right]\right)^{\frac{1}{1-\gamma}}}{\mathbb{E}_{t} \sum_{\tau=0}^{\infty} \lambda^{\tau} \beta^{\tau}\left(P_{t+\tau+1}\right)^{\gamma}\left(C_{t+\tau+1}\right)^{1-\sigma}}\right]
$$

The price level forecast for horizon $t+\tau$ of the firms that update their information set is

$$
\begin{aligned}
\mathbb{E}_{t}\left[P_{t+\tau}\right] & =\lambda \mathbb{E}_{t}\left[P_{t+\tau-1}\right]+(1-\lambda) \mathbb{E}_{t}\left[P_{t+\tau+1}^{*}\right] \\
& =\lambda^{\tau+1} P_{t-1}+\lambda^{\tau}(1-\lambda) P_{t}^{*}+\lambda^{\tau-1}(1-\lambda) \mathbb{E}_{t}\left[P_{t+1}^{*}\right]+\ldots+(1-\lambda) \mathbb{E}_{t}\left[P_{t+\tau}^{*}\right]
\end{aligned}
$$

which corresponds to the following inflation forecast

$$
\pi_{t+\tau}^{e, *}=\frac{\lambda \mathbb{E}_{t}\left[P_{t+\tau-1}\right]+(1-\lambda) \mathbb{E}_{t}\left[P_{t+\tau}^{*}\right]}{\mathbb{E}_{t}\left[P_{t+\tau-1}\right]}=\lambda+(1-\lambda) \frac{\mathbb{E}_{t}\left[P_{t+\tau}^{*}\right]}{\mathbb{E}_{t}\left[P_{t+\tau-1}\right]}
$$

On the other hand, because a fraction $\lambda$ of the firms do not adjust their information set (and prices) - and therefore ignore any information they might have about the stochastic process of the aggregate state of the world - it is fair to assume that they will also ignore this information when predicting the future evolution of prices. Therefore, these firms produce a constant forecast for $P_{t+\tau}$ over all horizons $t+\tau$, which will be the same as the one for the current period

$$
\mathbb{E}_{t} P_{t+\tau}^{-*}=\mathbb{E}_{t} P_{t}^{-*}=P_{t-1}
$$

where $\mathbb{E}_{t} P_{t}^{-*}$ is the price level forecast of the firms that do not update their information set. ${ }^{18}$ As a result, the inflation forecast for future periods of the agents with sticky information is equal to zero (i.e., $\pi_{t+\tau}^{-*, e}=0$ for all $\tau) .{ }^{19}$

To summarize, in this setting one group of firms of size $1-\lambda$ forecasts inflation for future periods to be consistent with the expected evolution of the aggregate state of the world $s_{t}$. Another group of firms of size $\lambda$ (with sticky information) forecasts inflation for future periods to be zero. Hence, the dispersion of inflation expectations for any horizon $t+\tau$ is given by

$$
\begin{aligned}
d_{t+\tau \mid t} & =\max \left|\pi_{t+\tau}^{e, *}-\mathbb{E}_{t}\left[\pi_{t+\tau}^{e}\right]\right|,\left|\pi_{t+\tau}^{e,-*}-\mathbb{E}_{t}\left[\pi_{t+\tau}^{e}\right]\right| \\
& =\max \left|\pi_{t+\tau}^{e, *}-\left[\lambda \pi_{t+\tau}^{e,-*}+(1-\lambda) \pi_{t+\tau}^{e, *}\right]\right|,\left|\pi_{t+\tau}^{e,-*}-\left[\lambda \pi_{t+\tau}^{e,-*}+(1-\lambda) \pi_{t+\tau}^{e, *}\right]\right| \\
& =\lambda\left|\left(\pi_{t+\tau}^{e, *}-\pi_{t+\tau}^{e,-*}\right)\right| \\
& =\lambda\left|\pi_{t+\tau}^{e, *}\right|
\end{aligned}
$$

\footnotetext{
${ }^{18}$ As firms with sticky information do not update their information set, they do not observe the value of the variables in the economy even in the current period.

${ }^{19}$ Firms with sticky information might have updated their information set in $t-1$, but by assuming that they do not change their prices in $t$, sticky information models de facto assume that those firms do not use any past information to make their decisions or update their expectations.
} 
Equation (34) indicates that the dispersion of inflation expectations moves in the same way of the absolute value of expected inflation of the firms with full information $\left|\pi_{t+\tau}^{e, *}\right|$. That is, both inflation expectations and the the dispersion of inflation expectations are state contingent.

Figure 7 shows the dispersion of $\tau$-period ahead inflation expectations when information stickiness is constant. ${ }^{20}$ In panel $7 \mathrm{a}$, the stochastic process of the aggregate state of the economy is assumed to be iid; in panel $7 \mathrm{~b}$, it is assumed to be persistent. The panels show the dispersion of inflation expectations for the average-size realization of total factor productivity and for two realizations of interest rate: an medium size shock (one standard deviation) and a large shock (corresponding to three standard deviations).

Figure 7: Response of Inflation Expectation Dispersion to an Interest Rate Shock, Constant Stickiness (Percentage points)

(a) i.i.d state of the economy

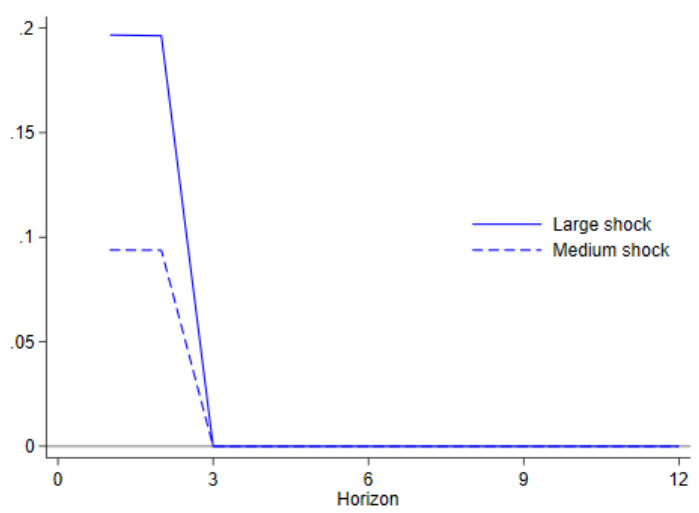

(b) Persistent state of the economy

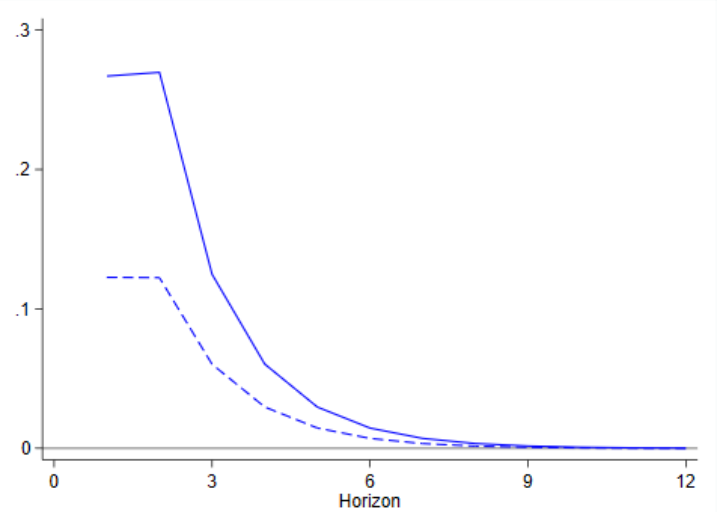

Source: Authors' calculations.

Notes: The solid and dash blue lines denote the responses of inflation expectation dispersion to large (three standard deviation) and a medium (one standard deviation) interest rate shocks, respectively.

When the process for the state of the economy exhibits low or zero persistence - behaving similar to an i.i.d process - the price expectations of the agents with full information over different horizons will be almost identical, $P_{t+1}^{e, *} \approx P_{t+2}^{e, *} \approx \ldots \approx P_{t+\tau}^{e, *}$, independent of the state of the world in period $t$. Hence, the dispersion of inflation expectations following an aggregate shock (i.e., an interest rate shock in the figures) increases exclusively because of differences in forecasts between the two groups of firms (those updating their information sets and those with sticky information) in $t$ and $t+1$. For $t$, the forecasters that update their information forecast and inflation consistent with the actual realization of inflation $\pi_{t}^{e, *}=\frac{P_{t}}{P_{t-1}}$ while the forecasters with sticky information forecast $\pi_{t}^{e,-*}=0$. For $t+1$, firms with sticky information are still forecasting zero inflation while the forecasters that update their information are forecasting $\pi_{t+1}=\frac{\mathbb{E}[P]}{P_{t}}$. From $t+2$ onwards, both groups forecast the same inflation $\pi_{t+\tau}^{e, *}=\pi_{t+\tau}^{e,-*}=0$, even when their price forecasts are different: the price forecast for those updating their information set is $\mathbb{E}[P]$ for all future periods, and the price forecast of those with sticky information is $P_{t-1}$. In contrast, if the stochastic process for the state of the economy exhibits a high degree of autocorrelation (in this case, $\rho^{z}=0.9$ and $\rho^{i}=0.5$ ), $\pi_{t+\tau}^{e, *}$ changes slowly over the forecast horizon moving eventually towards zero. However, depending on the initial state

\footnotetext{
${ }^{20}$ To be consistent with previous studies, we set $\lambda=0.78$ (i.e. about 22 percent of the firms change their prices in any given period.
}

\section{CInternational Monetary Fund. Not for Redistribution}


of the economy, the absolute value of inflation expectations might increase for some horizons before moving towards zero.

To obtain a measure of inflation expectation dispersion that is comparable to the empirical counterpart in Figure 5, we proceed as follows. First, we simulate 500 time series with 3,000 periods each, and discard the first 1,500 periods. Second, for each of the 500 time series, we extract all the 12-month sequences that start with the interest rate being equal to its unconditional mean (i.e., $i=\mathbb{E}(i)$ ). And third, we compute the average of the interest rate shock in absolute value $\left(\left|i_{t}-i_{t-1}\right|=77\right.$ basis points $)$ and the average response of inflation expectation dispersion. In Figure 8, we plot the average inflation expectation dispersion following an average interest rate shock and compare it to the rescaled empirical counterpart. The results indicate that the dispersion of inflation expectation decreases as the horizon gets larger, in line with the empirical findings, but the magnitude of the effect is smaller.

Figure 8: Average Response of Inflation Expectation Dispersion to an Interest Rate Shock, Constant Stickiness

(Percentage points)

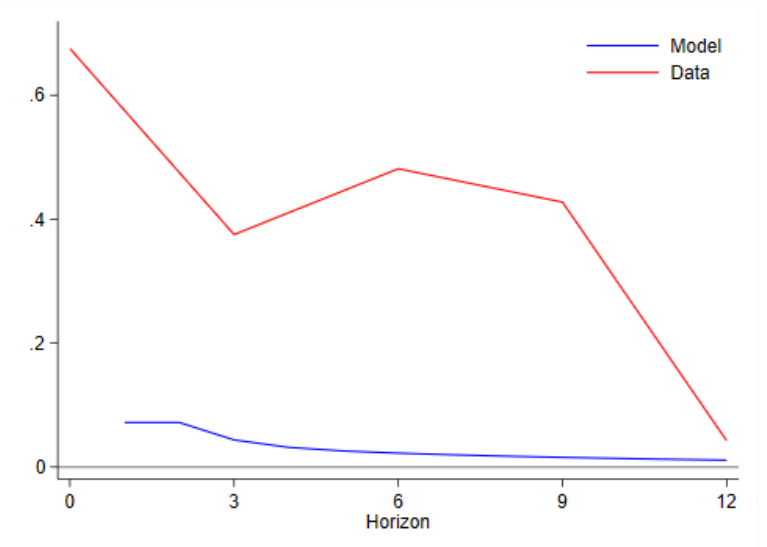

Source: Authors' calculations.

Notes: The blue line denotes the response of inflation expectation dispersion to a 77 basis point interest rate shock based on model simulations and the red line denotes the empirical response rescaled to a shock of the same size.

How does the degree of information stickiness affect the response of the dispersion of inflation forecasts? For any given future horizon $t+\tau$, the magnitude of the dispersion of inflation expectations depends on the degree of information stickiness in two ways. First, information stickiness affects the dispersion of expectations through its impact on the consensus forecast: when $\lambda$ is large, the consensus forecast will be biased towards forecasting zero inflation, and the distance between the consensus forecast and the forecast of the firms updating their information sets will be larger. Second, information stickiness has an effect on the optimal price setting of the firms updating their information sets, which will weight more heavily the future (compared to the present) when $\lambda$ is larger; thus, the price level of the economy will tend to be more stable (change less) for higher levels of information stickiness, and this smoothness in prices will dampen the dispersion of expectations. As a result, the net effect of information stickiness on the dispersion of inflation expectations cannot be pinned down unambiguously without numerical methods.

To illustrate this point, in Figure 9 we report the dispersion of inflation expectations for different degrees

\section{CInternational Monetary Fund. Not for Redistribution}


of information stickiness: a high degree $(\lambda=0.92$, that is much higher than in the baseline), a medium degree $(\lambda=0.5)$, and a low degree $(\lambda=0.08)$. Panel $9 \mathrm{a}$ and $9 \mathrm{~b}$ show the response of inflation expectation dispersion to large and medium-size interest rate shocks, respectively. The results suggest that for the parameters used in the calibration of the model, the magnitude of the dispersion of inflation expectations falls with the value of $\lambda$, though the relation is not linear as for $\lambda=0$ and for $\lambda=1$ there is no dispersion.

Figure 9: Response of Inflation Expectation Dispersion to a Persistent Interest Rate Shocks, Varying Stickiness

(Percentage points)

(a) Large interest rate shock

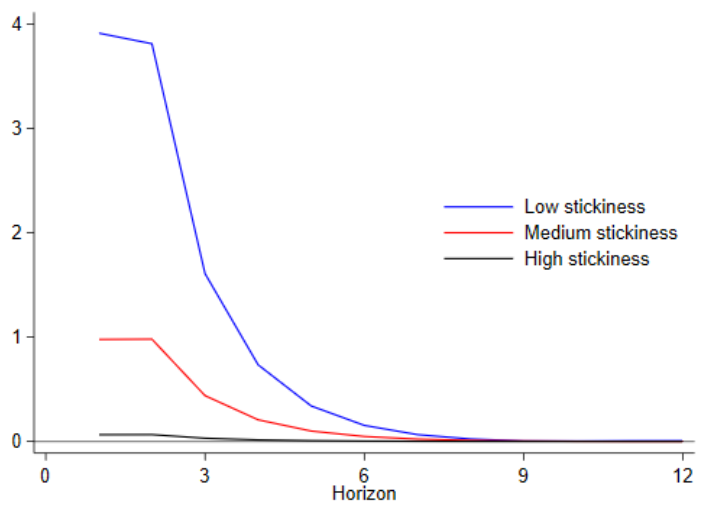

(b) Medium interest rate shock

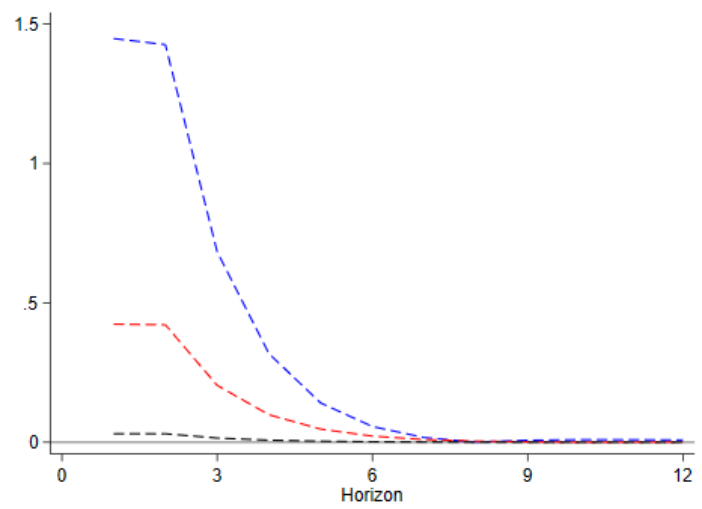

Source: Authors' calculations.

Notes: The figure shows the responses of inflation expectation dispersion to large (three standard deviations) and medium (one standard deviation) interest rate shocks, for different degrees of information stickiness: low $(\lambda=0.08)$, medium $(\lambda=0.50)$, and high $(\lambda=0.92)$.

All in all, these exercises show that models incorporating information stickiness generate results qualitatively consistent with the observed time path of the dispersion of inflation expectations in the United States. Yet, for values of the stickiness parameter consistent with the ones of the literature, the assumption of a constant degree of information rigidity is not sufficient to generate the magnitude of the dispersion observed in the data.

\subsection{Aggregate State-Dependent Degree of Information Rigidity}

Based on the literature finding that the degree of stickiness of information is not constant but rather state dependent (Mankiw et al., 2003), we now assume that the degree of information stickiness is lower in periods when the aggregate state of the economy $s_{t}=\left\{z_{t}, i_{t}\right\}$ is farther away from its mean realization. Formally ${ }^{21}$

$$
\begin{aligned}
\lambda_{t} & =\lambda \digamma\left(\Delta_{t}^{z}, \Delta_{t}^{i}\right) \\
\Delta_{t}^{z} & =\left|z_{t}-\mathbb{E}[z]\right| \\
\Delta_{t}^{i} & =\left|i_{t}-\mathbb{E}[i]\right|
\end{aligned}
$$

We then define two thresholds for the distance of the aggregate states from the mean realization of the

\footnotetext{
${ }^{21}$ The functional form is $\lambda_{t}=\bar{\lambda} /\left[\left(1+\psi_{1}\left|z_{t}-\mathbb{E}[z]\right|\right)\left(1+\psi_{2}\left|i_{t}-\mathbb{E}[i]\right|\right)\right]$, with $\psi_{1}=\psi_{2}=3$.
} 
shocks

$$
\begin{aligned}
\widetilde{\Delta^{z}} & =|\widetilde{z}-\mathbb{E}[z]| \\
\widetilde{\Delta^{i}} & =\widetilde{i}-\mathbb{E}[i] \mid
\end{aligned}
$$

so that we have

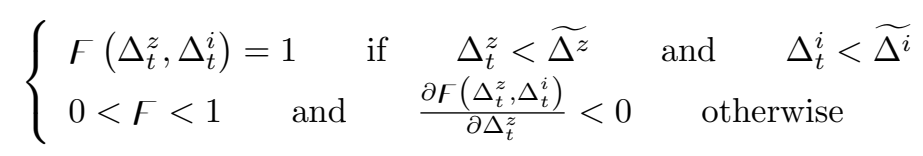

In a world characterized by this type of state-dependent information stickiness, the price of the firms that update their information set is

$$
P_{t}^{*}=\frac{\gamma}{\gamma-1}\left[\frac{\mathbb{E}_{t} \sum_{\tau=0}^{\infty} \lambda_{t+\tau} \beta^{\tau}\left(P_{t+\tau}\right)^{\gamma}\left(C_{t+\tau}\right)^{1-\sigma}\left(\alpha_{1} z_{t+\tau}+\alpha_{2} i_{t+\tau}\right)\left(\mathbb{E}\left[\vartheta^{1-\gamma}\right]\right)^{\frac{1}{1-\gamma}}}{\mathbb{E}_{t} \sum_{\tau=0}^{\infty} \lambda_{t+\tau} \beta^{\tau}\left(P_{t+\tau}\right)^{\gamma}\left(C_{t+\tau}\right)^{1-\sigma}}\right]
$$

the price index of the economy is

$$
P_{t}=\lambda_{t} P_{t-1}+\left(1-\lambda_{t}\right) P_{t}^{*}
$$

and the dispersion of inflation expectation is

$$
d_{t+\tau \mid t}=\lambda_{t+\tau}\left|\pi_{t+\tau}^{e, *}\right|
$$

where $\lambda_{t+\tau}$ in "extreme" states of the world (i.e., farther away from the mean realization of those states) is smaller than in normal states, but $\pi_{t+\tau}^{e, *}$ is larger. Regardless of which of the two effects prevails, the dispersion of inflation expectations depends more on the realizations of the aggregate states of the world than when information stickiness is constant. This is because $\pi_{t+\tau}^{e, *}$ and $\lambda_{t+\tau}$ are both state dependent.

Figure 10 shows the dispersion of inflation expectations when information stickiness is state contingent. The results can be compared to the corresponding panels for the constant information stickiness case in Figure 7. For moderate realizations of the productivity shock (i.e., $z_{5}$ ), both time path and the magnitude of the dispersion of inflation expectations is very similar. However, for more extreme realizations of the productivity shock (i.e., $z_{1}$ and $z_{9}$ ), the time path remains similar and the magnitude of the dispersion is much larger in the case of state contingent information stickiness. As shown in Figure 11, however, the size of the response of the average dispersion of inflation expectations to the average interest rate shock is still one order of magnitude below the one observed in the United States data.

Compared to the results of the case with constant degree of information stickiness, the dispersion of inflation expectations depends more heavily on the realization of the states of the economy. This is because, when information stickiness is state contingent, firms adjust prices more than in the case with a constant degree of information stickiness if state realizations are extreme, contributing to larger fluctuations of the price level across states of the world. These larger price responses, in turn, become part of the firms' information sets and will affect the formation of their inflation expectations. Specifically, these firms will expect movements in prices, and therefore the changes in those prices to be larger when the economy is in extreme states. Firms with sticky information, on the other hand, will not update their inflation expectations (which are zero as in the case of constant stickiness of information). As a result, the distance between the inflation forecasts of firms with sticky information and those updating their information sets is larger in 
Figure 10: Response of Inflation Expectation Dispersion to a Persistent Interest Rate Shock, Aggregate State-Contingent Information Stickiness

(Percentage points)

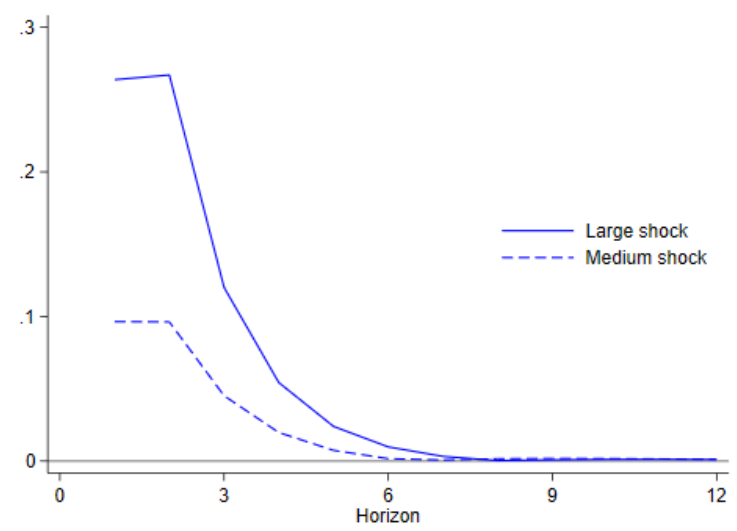

Source: Authors' calculations.

Notes: The solid and dash blue lines denote the responses of inflation expectation dispersion to large (three standard deviations) and medium (one standard deviation) interest rate shocks, respectively.

Figure 11: Average Response of Inflation Expectation Dispersion to an Interest Rate Shock, Aggregate State-Contingent Information Stickiness

(Percentage points)

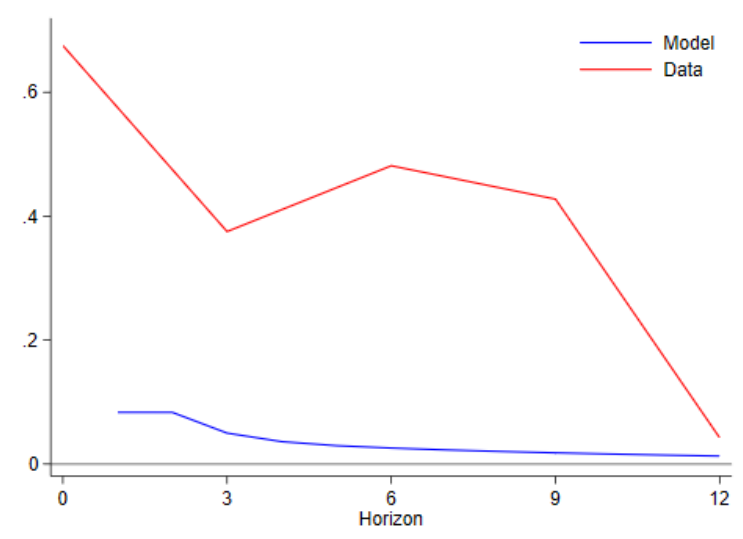

Source: Authors' calculations.

Notes: The blue line denotes the response of inflation expectation dispersion to a 77 basis point interest rate shock based on model simulations and the red line denotes the empirical response rescaled to a shock of the same size.

extreme states than in the case when information stickiness is constant.

\subsection{Firm State-dependent Degree of Information Rigidity}

If the degree of information stickiness depends on the firms' states $\vartheta_{t}^{j}$ rather than the aggregate state $s_{t}$, firms' prices $p_{t}^{j}$ as well as aggregate variables will depend on the distribution of the idiosyncratic shocks, and 
not simply on their mean realization.

Similar to the case in which the degree of information stickiness depends on the aggregate states, we assume that for idiosyncratic shocks above some threshold level $\widetilde{\vartheta}$, the degree of information stickiness will be lower than a constant given level $\lambda$, and the stickiness will be a decreasing function of the distance between the actual shock realization and the mean level of those shocks. Firms with idiosyncratic shocks above $\widetilde{\vartheta}$ find themselves in extreme circumstances (either very good or very bad realizations of their productivity), and will care relatively more about the present than firms with more moderate realizations of their individual shocks.

All firms updating their information sets are aware of this differentiation in the behavior of firms that update their prices in the current period. Because shocks are idiosyncratic and the distribution of those shocks is time invariant, the share of firms with lower levels of $\lambda_{t+\tau}$ is constant in all periods. Nevertheless, the share of firms in extreme conditions in each period will affect the average price level in the economy.

In a world characterized by idiosyncratic state-dependent information stickiness, the optimal price chosen by the firms that update their information set and prices in period $t$ is

$$
P_{t}^{j}=\frac{\gamma}{\gamma-1}\left[\frac{\mathbb{E}_{t} \sum_{\tau=0}^{\infty} \lambda_{t+\tau}^{j}\left(\vartheta_{t+\tau}^{j}\right) \beta^{\tau}\left(P_{t+\tau}\right)^{\gamma}\left(C_{t+\tau}\right)^{1-\sigma}\left(\alpha_{1} z_{t+\tau}+\alpha_{2} i_{t+\tau}\right) \vartheta_{t+\tau}^{j}}{\mathbb{E}_{t} \sum_{\tau=0}^{\infty} \lambda_{t+\tau}^{j}\left(\vartheta_{t+\tau}^{j}\right) \beta^{\tau}\left(P_{t+\tau}\right)^{\gamma}\left(C_{t+\tau}\right)^{1-\sigma}}\right]
$$

where $^{22}$

$$
\lambda_{t+\tau}^{j}=\lambda \digamma\left(\Delta_{t+\tau}^{\vartheta^{j}}\right)
$$

and

$$
\left\{\begin{array}{l}
\digamma\left(\Delta_{t+\tau}^{\vartheta^{j}}\right)=1 \quad \text { if } \quad \Delta_{t+\tau}^{\vartheta^{j}}<\widetilde{\Delta^{\vartheta}} \\
0<\digamma\left(\Delta_{t+\tau}^{\vartheta^{j}}\right)<1 \quad \text { and } \quad \frac{\partial \digamma\left(\Delta_{t+\tau}^{\vartheta^{j}}\right)}{\partial \Delta_{t+\tau}^{\vartheta^{j}}}<0 \quad \text { otherwise }
\end{array}\right.
$$

The overall price index can be computed as the sum of different sub-indexes. The first sub-index is the one that aggregates the prices of the firms with moderate realizations of their idiosyncratic shocks (i.e., $\left.\vartheta_{t+\tau} \leq \widetilde{\vartheta}\right)$; these firms have a weight in the total population of firms of $\mu^{\widetilde{\vartheta}}$ and, of these, a share $1-\lambda$ changes its prices in this period and a share $\lambda$ sets their prices to $P_{t}^{j}=P_{t-1}^{j}$. The second sub-index is the one that aggregates the prices of the firms with extreme realizations of their idiosyncratic shocks (i.e., $\vartheta_{t+\tau}>\widetilde{\vartheta}$; ; these firms have a weight in the total population of firms of $1-\mu^{\widetilde{\vartheta}}$, and, of these, a share $1-\lambda * E\left[\digamma\left(\Delta_{t}^{\vartheta^{j}}\right) \mid\left(\vartheta^{j}>\widetilde{\vartheta}\right)\right]$ changes its prices in this period and a share $\lambda * E\left[\digamma\left(\Delta_{t}^{\vartheta^{j}}\right) \mid\left(\vartheta^{j}>\tilde{\vartheta}\right)\right]$ sets their prices to $P_{t}^{j}=P_{t-1}^{j}$.

The price index of the economy is then given by:

$$
\begin{aligned}
P_{t} & =\lambda\left(\mu^{\widetilde{\vartheta}}+\left(1-\mu^{\widetilde{\vartheta}}\right) E\left[\digamma\left(\Delta_{t}^{\vartheta^{j}}\right) \mid\left(\vartheta^{j}>\widetilde{\vartheta}\right)\right]\right) P_{t-1} \\
& +\mu^{\widetilde{\vartheta}}(1-\lambda) P_{t}^{*, \widetilde{\vartheta}} \\
& +\left(1-\mu^{\widetilde{\vartheta}}\right)\left(1-\lambda * E\left[\digamma\left(\Delta_{t}^{\vartheta^{j}}\right) \mid\left(\vartheta^{j}>\widetilde{\vartheta}\right)\right]\right) P_{t}^{*,-\widetilde{\vartheta}}
\end{aligned}
$$

where the sub-index of the optimal prices for firms with moderate realizations of their productivity shocks

\footnotetext{
${ }^{22}$ The functional form is $\lambda_{t}^{j}=\bar{\lambda} /\left[\left(1+\psi_{3}\left|\vartheta_{t}^{j}-\mathbb{E}[\vartheta]\right|\right)\right]$, where $\psi_{3}=3$.
} 


$$
\begin{aligned}
& P_{t}^{*, \widetilde{\vartheta}}= \\
& \frac{\gamma}{\gamma-1}\left\{\int_{0}^{\widetilde{\vartheta}}\left[\frac{\mathbb{E}_{t} \sum_{\tau=0}^{\infty} \lambda^{\tau}\left(\prod_{h=0}^{\tau} \digamma\left(\vartheta_{t+h}^{j}\right)\right) \beta^{\tau}\left(P_{t+\tau}\right)^{\gamma}\left(C_{t+\tau}\right)^{1-\sigma}\left(\alpha_{1} z_{t+\tau}+\alpha_{2} i_{t+\tau}\right) \vartheta_{t+\tau}^{j}}{\mathbb{E}_{t} \sum_{\tau=0}^{\infty} \lambda^{\tau}\left(\prod_{h=0}^{\tau} \digamma\left(\vartheta_{t+h}^{j}\right)\right) \beta^{\tau}\left(P_{t+\tau}\right)^{\gamma}\left(C_{t+\tau}\right)^{1-\sigma}}\right] j\right\}^{1-\gamma}
\end{aligned}
$$

and the sub-index of the optimal prices of firms with extreme realizations of their productivity shocks is:

$$
\begin{aligned}
& P_{t}^{*,-\widetilde{\vartheta}}= \\
& \frac{\gamma}{\gamma-1}\left\{\int_{\widetilde{\vartheta}}^{1}\left[\frac{\mathbb{E}_{t} \sum_{\tau=0}^{\infty} \lambda^{\tau}\left(\prod_{h=0}^{\tau} \digamma\left(\vartheta^{j}\right)\right) \beta^{\tau}\left(P_{t+\tau}\right)^{\gamma}\left(C_{t+\tau}\right)^{1-\sigma}\left(\alpha_{1} z_{t+\tau}+\alpha_{2} i_{t+\tau}\right) \vartheta_{t+\tau}^{j}}{\mathbb{E}_{t} \sum_{\tau=0}^{\infty} \lambda^{\tau}\left(\prod_{h=0}^{\tau} \digamma\left(\vartheta^{j}\right)\right) \beta^{\tau}\left(P_{t+\tau}\right)^{\gamma}\left(C_{t+\tau}\right]^{1-\sigma}} d j\right\}^{\frac{1}{1-\gamma}}\right.
\end{aligned}
$$

Since $P_{t}^{*,-\widetilde{\vartheta}}$ is the average price of firms with extreme realizations of their productivity shocks, it corresponds to a weighted sum of individual firms' prices that are much higher and much lower than the individual firms' prices in $P_{t}^{*, \widetilde{\vartheta}}$, as those prices average over in $P_{t}^{*,-\widetilde{\vartheta}}$ correspond to more extreme realizations of the individual idiosyncratic shocks, and the firms experiencing those shocks exhibit a lower degree of information stickiness and place a relatively higher weight on the current conditions in comparison to firms with moderate realizations of their productivity. The concavity of the price index function implies that $P_{t}^{*, \widetilde{\vartheta}}>P_{t}^{*,-\widetilde{\vartheta}}$.

Defining

$$
\widetilde{\digamma}=E\left[\digamma\left(\Delta_{t}^{\vartheta^{j}}\right) \mid\left(\vartheta^{j}>\widetilde{\vartheta}\right)\right]
$$

we can rewrite $P_{t}$ as

$$
P_{t}=\lambda\left[\mu^{\widetilde{\vartheta}}+\left(1-\mu^{\widetilde{\vartheta}}\right) \widetilde{\digamma}\right] P_{t-1}+\mu^{\widetilde{\vartheta}}(1-\lambda) P_{t}^{*, \widetilde{\vartheta}}+\left(1-\mu^{\widetilde{\vartheta}}\right)(1-\lambda \widetilde{\digamma}) P_{t}^{*,-\widetilde{\vartheta}}
$$

Iterating this expression forward, we obtain the following expression for the expected value of the next period price level for the forecasters that are processing new information in $t$

$$
\mathbb{E}_{t}\left[P_{t+1}\right]=\lambda\left(\mu^{\widetilde{\vartheta}}+\left(1-\mu^{\widetilde{\vartheta}}\right) \widetilde{\digamma}\right) P_{t}+\mu^{\widetilde{\vartheta}}(1-\lambda) \mathbb{E}_{t}\left[P_{t+1}^{*, \widetilde{\vartheta}}\right]+\left(1-\mu^{\widetilde{\vartheta}}\right)(1-\lambda \widetilde{\digamma}) \mathbb{E}_{t}\left[P_{t+1}^{*,-\widetilde{\vartheta}}\right]
$$

Doing the same for all future periods, the forecast of the price level for horizon $t+\tau$ is

$$
\mathbb{E}_{t}\left[P_{t+\tau}\right]=\lambda\left(\mu^{\widetilde{\vartheta}}+\left(1-\mu^{\widetilde{\vartheta}}\right) \widetilde{\digamma}\right) \mathbb{E}_{t} P_{t+\tau-1}+\mu^{\widetilde{\vartheta}}(1-\lambda) \mathbb{E}_{t}\left[P_{t+\tau}^{*, \widetilde{\vartheta}}\right]+\left(1-\mu^{\widetilde{\vartheta}}\right)(1-\lambda \widetilde{\digamma}) \mathbb{E}_{t}\left[P_{t+\tau}^{*,-\widetilde{\vartheta}}\right]
$$

Therefore, firms updating their information set in period $t$ will have the following inflation forecast for 
horizon $t+\tau$

$$
\begin{aligned}
\pi_{t+\tau}^{*, e} & =\frac{\lambda\left[\mu^{\widetilde{\vartheta}}+\left(1-\mu^{\widetilde{\vartheta}}\right) \widetilde{\digamma}\right] \mathbb{E}_{t}\left[P_{t+\tau-1}\right]+\mu^{\widetilde{\vartheta}}(1-\lambda) \mathbb{E}_{t}\left[P_{t+\tau}^{*, \widetilde{\vartheta}}\right]+\left(1-\mu^{\widetilde{\vartheta}}\right)(1-\lambda \widetilde{\digamma}) \mathbb{E}_{t}\left[P_{t+\tau}^{*,-\tilde{\vartheta}}\right]}{\mathbb{E}_{t}\left[P_{t+\tau-1}\right]} \\
& =\lambda\left[\mu^{\widetilde{\vartheta}}+\left(1-\mu^{\widetilde{\vartheta}}\right) \widetilde{\digamma}\right]+\mu^{\widetilde{\vartheta}}(1-\lambda) \frac{\mathbb{E}_{t}\left[P_{t+\tau}^{*}, \widetilde{\vartheta}\right]}{\mathbb{E}_{t}\left[P_{t+\tau-1}\right]}+\left(1-\mu^{\widetilde{\vartheta}}\right)(1-\lambda \widetilde{\digamma}) \frac{\mathbb{E}_{t}\left[P_{t+\tau}^{*,-\widetilde{\vartheta}}\right]}{\mathbb{E}_{t}\left[P_{t+\tau-1}\right]}
\end{aligned}
$$

Similar to the other cases discussed so far, the firms that do not update their information sets forecast inflation to be zero, and the dispersion of inflation expectations is given by

$$
\begin{aligned}
d_{t+\tau \mid t} & =\left|\pi_{t+\tau}^{e, *}-\left[\lambda\left(\mu^{\widetilde{\vartheta}}+\left(1-\mu^{\widetilde{\vartheta}}\right) \widetilde{\digamma}\right] \pi_{t+\tau}^{e,-*}+\left\{1-\lambda\left[\mu^{\widetilde{\vartheta}}+\left(1-\mu^{\widetilde{\vartheta}}\right) \widetilde{\digamma}\right]\right\} \pi_{t+\tau}^{e, *}\right]\right| \\
& =\lambda\left[\mu^{\widetilde{\vartheta}}+\left(1-\mu^{\widetilde{\vartheta}}\right) \widetilde{\digamma}\right]\left|\pi_{t+\tau}^{e, *}\right|
\end{aligned}
$$

From equation (54), it becomes clear that the lower the value of the threshold $\widetilde{\vartheta}$, the higher the weight of the term $\frac{\mathbb{E}_{t}\left[P_{t+\tau}^{*,-\tilde{\vartheta}}\right]}{\frac{\mathbb{E}_{t}\left[P_{t+\tau-1}\right]}{4}}$ in $\pi_{t+\tau}^{e, *}$. Additionally, a lower $\tilde{\vartheta}$ also implies a larger magnitude of $\frac{\mathbb{E}_{t}\left[P_{t+\tau}^{*,-\tilde{\vartheta}}\right]}{\mathbb{E}_{t}\left[P_{t+\tau-1}\right]}$, and other things given a larger magnitude of $\pi_{t+\tau}^{e, *} \cdot{ }^{23}$ Therefore, for lower thresholds of the idiosyncratic shock that result in a lower degree of information stickiness, the impact of the firm heterogeneity in the aggregate variables and the dispersion of inflation expectations is larger. One should note that while the heterogeneity across firms has an impact on the magnitude of the dispersion of inflation expectations, it does not have an impact on the term structure of inflation expectations due to the stationarity of the distribution of the idiosyncratic shocks.

Figure 12 shows the dispersion of inflation expectations for the different states of the economy when information stickiness varies across forecasters, and Figure 13 displays the average response of inflation expectation dispersion to the average interest rate shock. It is clear that heterogeneity in information stickiness across firms can go a long way in delivering a magnitude of the dispersion of the inflation expectations closer to the one observed one in the data (especially for aggregate states of the economy that are away from their mean realization). In fact, the magnitude of inflation dispersion is about four times larger than in the other cases and about half of what is observed in the data.

\section{Conclusions}

In this paper we provide evidence of causal effects of monetary policy surprises on inflation dispersion in the United States. Using daily data of federal funds rate forecasts and inflation expectations at the analyst level from major financial institutions, and an identification strategy that hinges on a tight window around the Fed meetings, we find that inflation expectation dispersion increases in response to monetary policy surprises. In particular, we show that dispersion increases for shorter horizons (up to nine months after the policy rate decision is taken), and that it then approaches zero over the horizon at which monetary policy has effects on prices.

To rationalize these results, we propose a partial equilibrium model with rational expectations and sticky

\footnotetext{
${ }^{23}$ Due to the concavity of the price index, both the numerator and denominator are likely to increase when $\widetilde{\vartheta}$ falls, but the numerator $\mathbb{E}_{t} P_{t+\tau}^{*, \widetilde{\vartheta}}$ increases by more than the denominator $\mathbb{E}_{t} P_{t+\tau-1}$ as the denominator gives a weight lower than one to the firms under extreme circumstances.
} 
Figure 12: Response of Inflation Expectation Dispersion to a Persistent Interest Rate Shock, Firm State-Contingent Information Stickiness

(Percentage points)

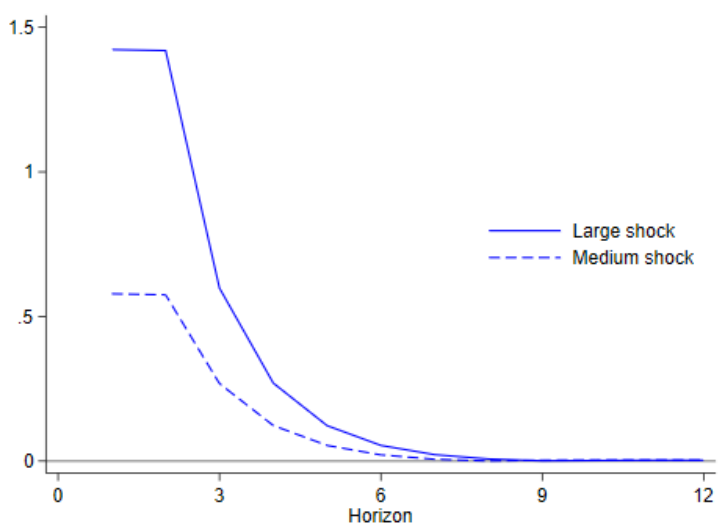

Source: Authors' calculations.

Notes: The solid and dash blue lines denote the responses of inflation expectation dispersion to a large and medium size interest rate shock, respectively.

Figure 13: Average Response of Inflation Expectation Dispersion to an Interest Rate Shock, Firm State-Contingent Information Stickiness

(Percentage points)

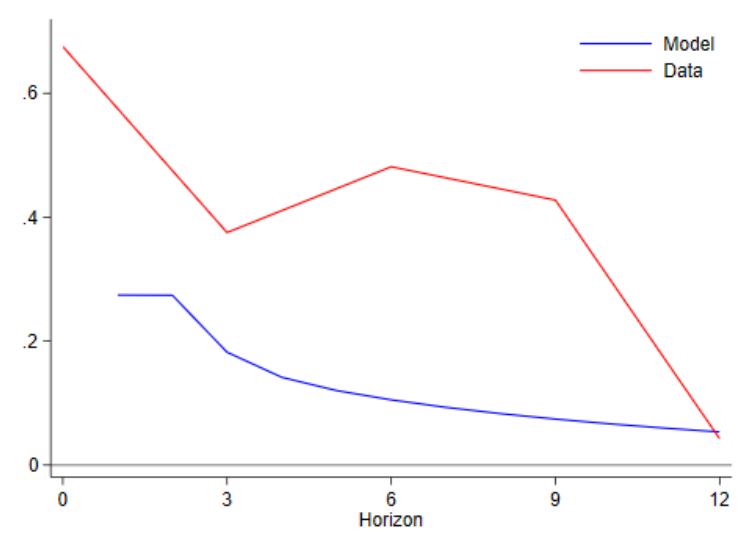

Source: Authors' calculations.

Notes: The blue line denotes the response of inflation expectation dispersion to a 77 basis point interest rate shock based on model simulations and the red line denotes the empirical response rescaled to a shock of the same size.

information in the spirit of Mankiw and Reis (2002). We show that, while full information models do not match neither quantitatively nor qualitatively the observed term structure of the dispersion of inflation expectations, sticky information models do. In particular, introducing sticky information results in a term structure of inflation expectation that shows dispersion at short horizons and fades away as the horizon becomes longer. When we allow the degree of information rigidity to depend on the realization of firmspecific shocks, the theoretical results are also quantitatively close to the empirical ones. 
Inflation expectation dispersion, even if at short horizons, can lead to price dispersion and inflation persistence. Thus, from a policy perspective, efforts should be directed at further refining the communication strategy of monetary policy so that information is more aligned across agents. This would allow to maintain inflation expectations better anchored even at shorter horizons, which is when the credit channel is less effective. 


\section{References}

Andrade, Philippe and Hervé Le Bihan (2013). "Inattentive Professional Forecasters". Journal of Monetary Economics 60(8), pp. 967-982.

Beechey, Meredith J, Benjamin K Johannsen, and Andrew T Levin (2011). "Are Long-Run Inflation Expectations Anchored More Firmly in the Euro Area than in the United States?" American Economic Journal: Macroeconomics 3(2), pp. 104-29.

Bems, Rudolfs, Francesca G. Caselli, Francesco Grigoli, Bertrand Gruss, and Weicheng Lian (2018). "Expectations' Anchoring and Inflation Persistence". IMF Working Paper 18/120.

Bernanke, Ben (2007). "Inflation Expectations and Inflation Forecasting". Board of Governors of the Federal Reserve System (US).

Bordalo, Pedro, Nicola Gennaioli, Yueran Ma, and Andrei Shleifer (2020). "Overreaction in Macroeconomic Expectations". American Economic Review 110(9), pp. 2748-2782.

Bordalo, Pedro, Nicola Gennaioli, and Andrei Shleifer (2018). "Diagnostic Expectations and Credit Cycles". Journal of Finance 73(1), pp. 199-227.

Brito, Steve, Yan Carriere-Swallow, and Bertrand Gruss (2018). "Disagreement about Future Inflation: Understanding the Benefits of Inflation Targeting and Transparency". International Monetary Fund Working Paper 18/24.

Capistrán, Carlos and Manuel Ramos-Francia (2010). "Does inflation targeting affect the dispersion of inflation expectations?" Journal of Money, Credit and Banking 42(1), pp. 113-134.

Carrière-Swallow, Yan, Bertrand Gruss, Nicolas Magud, and Fabian Valencia (2020). "Monetary Policy Credibility and Exchange Rate Pass-Through". International Journal of Central Banking forthcoming.

Coibion, Olivier and Yuriy Gorodnichenko (2012). "What Can Survey Forecasts Tell Us about Information Rigidities?" Journal of Political Economy 120(1), pp. 116-159.

Del Negro, Marco and Stefano Eusepi (2011). "Fitting Observed Inflation Expectations". Journal of Economic Dynamics and control 35(12), pp. 2105-2131.

Dovern, Jonas, Ulrich Fritsche, and Jiri Slacalek (2012). "Disagreement among forecasters in G7 countries". Review of Economics and Statistics 94(4), pp. 1081-1096.

Fuhrer, Jeffrey C (2010). "Inflation Persistence". Handbook of monetary economics. Vol. 3. Elsevier, pp. 423486.

Gertler, Mark and Peter Karadi (2015). "Monetary Policy Surprises, Credit Costs, and Economic Activity". American Economic Journal: Macroeconomics 7(1), pp. 44-76.

Gürkaynak, Refet S, Andrew Levin, and Eric Swanson (2010). "Does Inflation Targeting Anchor Long-Run Inflation Expectations? Evidence from the U.S., UK, and Sweden". Journal of the European Economic Association 8(6), pp. 1208-1242.

Gürkaynak, Refet S, Brian Sack, and Eric Swanson (2005). "The Sensitivity of Long-Term Interest Rates to Economic News: Evidence and Implications for Macroeconomic Models". American Economic Review 95(1), pp. 425-436.

Hoffmann, Mathias and Patrick Hürtgen (2016). "Inflation Expectations, Disagreement, and Monetary Policy". Economics Letters 146, pp. 59-63.

Jarociński, Marek and Peter Karadi (2020). "Deconstructing Monetary Policy Surprises-The Role of Information Shocks". American Economic Journal: Macroeconomics 12(2), pp. 1-43. 
Kumar, Saten, Hassan Afrouzi, Olivier Coibion, and Yuriy Gorodnichenko (2015). "Inflation Targeting Does Not Anchor Inflation Expectations: Evidence from Firms in New Zealand". Brookings Papers on Economic Activity 46(2 Fall), pp. 151-225.

Lorenzoni, Guido (2009). "A Theory of Demand Shocks". American Economic Review 99(5), pp. 2050-2084.

Mackowiak, Bartosz and Mirko Wiederholt (2009). "Optimal Sticky Prices under Rational Inattention". American Economic Review 99(3), pp. 769-803.

Mankiw, N Gregory and Ricardo Reis (2002). "Sticky Information versus Sticky Prices: A Proposal to Replace the New Keynesian Phillips Curve". Quarterly Journal of Economics 117(4), pp. 1295-1328.

Mankiw, N Gregory, Ricardo Reis, and Justin Wolfers (2003). "Disagreement about Inflation Expectations". National Bureau of Economic Research Macroeconomics Annual 18, pp. 209-248.

Melosi, Leonardo (2017). "Signalling Effects of Monetary Policy". Review of Economic Studies 84(2), pp. 853884 .

Mishkin, Frederic S (2007). "Inflation Dynamics". International Finance 10(3), pp. 317-334.

Nakamura, Emi and Jón Steinsson (2018). "High-Frequency Identification of Monetary Non-Neutrality: The Information Effect". Quarterly Journal of Economics 133(3), pp. 1283-1330.

Patton, Andrew J and Allan Timmermann (2010). "Why Do Forecasters Disagree? Lessons from the Term Structure of Cross-Sectional Dispersion". Journal of Monetary Economics 57(7), pp. 803-820.

Ramey, Valerie A (2016). "Macroeconomic Shocks and Their Propagation". Handbook of Macroeconomics 2, pp. 71-162.

Romer, Christina D and David H Romer (2004). "A New Measure of Monetary Shocks: Derivation and Implications". American Economic Review 94(4), pp. 1055-1084.

Sims, Christopher A (2003). "Implications of Rational Inattention". Journal of Monetary Economics 50(3), pp. 665-690.

Woodford, Michael (2003). "Imperfect Common Knowledge and the Effects of Monetary Policy". National Bureau of Economic Research Woring Paper No. 8673. 


\section{Appendix A. Model parameters}

Table A.1 reports the values of the parameters of the model.

Table A.1: Parameter Values

\begin{tabular}{lcc}
\hline Parameter & Notation & Value \\
\hline Average interest rate & $\bar{i}$ & 0.004075 \\
Capital to output ratio & $K / Y$ & 3 \\
Discount factor & $\beta$ & $(1 / 10.4)^{1 / 12}$ \\
Elasticity of substitution between intermediate goods & $\gamma$ & 34 \\
Information rigidity & $\bar{\lambda}$ & 0.78 \\
Persistence of idiosyncratic firms' shocks & $\rho_{\vartheta}$ & 0.92 \\
Persistence of interest rate shocks & $\rho_{i}$ & 0.5 \\
Persistence of productivity shocks & $\rho_{z}$ & 0.89875 \\
Risk aversion & $\sigma$ & 2 \\
Standard deviation of idiosyncratic firms' shocks & $\sigma_{\vartheta}^{2}$ & 0.05 \\
Standard deviation of interest rate shocks & $\sigma_{i}^{2}$ & 0.0007 \\
Standard deviation of productivity shocks & $\sigma_{i}^{2}$ & 0.00275 \\
\hline
\end{tabular}

